\title{
Considerations on General
}

\section{Methodological Assumptions \\ of the Sciences of Sport}

Authors' contribution:

A) conception and design of the study

B) acquisition of data

C) analysis and interpretation of data

D) manuscript preparation

E) obtaining funding

\section{Jerzy Kosiewicz}

Josef Pilsudski University of Physical Education in Warsaw, Poland

\section{ABSTRACT}

The considerations included in the article are the result of several years of teaching general methodology for doctoral studies at Josef Pilsudski University of Physical Education in Warsaw.

The presented text consists of two basic parts. The first includes reminiscences and associated methodological resentment. The second presents a wide panorama of standpoints concerning functions and kinds of hypotheses, their role and significance in contemporary research programs of formal, empirical (connected with natural sciences and biology), and humanities nature. Sketchy and encyclopaedic interpretations, presented in the context of commentaries by the author of this paper, thereby dominate.

The aim of the first part is to draw attention to some methodological mistakes which often appear and which have become common in some academic milieus to such a degree that some intervention and postulatory correction, referring to Polish and Western methodological literature, is advisable. These shortcomings are connected, among other things, with the structure of the scientific work, with the formulation and application of hypotheses, with relations taking place between the general methodology and specialized methodologies, kinds and types of research work, with reliability of information on sources of creative information, as well with the category of verification in its relation, on the one hand, to confirmation and corroboration, and on the other hand, to testing, checking, falsification, and terms close in meaning to the last one.

The abovementioned resentment results, first of all, from the fact that the authors discussed in the first part usually insist on erroneous solutions, negating a priori, without becoming acquainted with the literature on the subject or making attempts to explain or initiate a methodological argument referring to sources and studies.

That resentment is significant, among other things, in the causal sense - that is, because of the fact that, firstly, it justifies and substantiates the need for a statement presenting controversial questions in a content-related and formal way. Secondly, because thanks to such (that is, cognitive-emotional) introduction, the whole argument - not only in the first, but also in the second part - is much more interesting. It is saturated with authenticity. Many readers know the figures mentioned and are familiar with their - sometimes too insouciant (sometimes not very reliable) - attitudes to important issues from the field of research methods. It is also interesting why the people cited make mistakes. Hence, it is also advisable to look at a wider methodological context of justification (included in the much longer second part) dedicated to perhaps the most thorough characteristics of the hypothesis in the literature on the subject, which is available to the author. Without presentation 
of the controversial issues in the first part, the second part, more important from the methodological viewpoint, might be omitted by a considerable proportion of readers. In that part attention is paid mainly to issues concerning working, initial, zero, primary, introductory, directing, gradual, auxiliary, ad hoc auxiliary, bridge, futile and true, dangerous and safe, quite natural and neutral, individual and general, complete and incomplete, deep, strong, probabilistic and non-probabilistic (that is, deterministic), related, falsifying, basic, psychological, metaphysical and materialist hypotheses, as well as those concluding ones - that is, those constituting the final effect of definite (concluded here and now) research; hence, those which have undergone verification, confirmation, corroboration or modification as those which predict and explain a given research problem in the best possible way.

KEYWORDS methodology, hypothesis, research procedure.

\section{Methodological reminiscences}

At the Josef Pilsudski University of Physical Education in Warsaw - similar to other schools of that type from both the public and private sector - there appear academic arguments concerning structures and methodological assumptions of various types of research. They refer both to strictly scientific dissertations (for example to $\mathrm{PhD}$ or habilitation theses) and to research work connected with the teaching process Bachelors or Masters theses - that is, mainly to research of the following qualities:

1. From the field of the humanities - philosophy, sociology, pedagogy, history of physical culture or sport, etc. (the humanities are understood by me as by Kazimierz Ajdukiewicz, 1995, pp. 287-313).

2. Biological ones - concerning biology, physiology, anatomy, biomechanics, biochemistry, biophysics, etc.

3. Research connected with the widely and narrowly understood theory of sport, as well as with the widely and narrowly understood theory of recreation.

That classification should be supplemented with four remarks pointing out that:

1. Methodology of physical education, methodology of physical education of the disabled, and the theory of physical education - including theory of physical education of the disabled - may also be included among the humanities, since they are, both in the content-related and methodological sense, derivatives and specifications of pedagogy, which is divided into education, didactics, methodology and the theory of pedagogy. In the field of the forms of methodology mentioned, their connections with the humanities are natural. The same applies to the theory of physical education, which is a derivative and a more specific form of education. By the way, according to Maciej Demel (a theoretician of physical and health education as well as a physician) the basis of methodology of physical education is constituted by the theory of physical education, and the basis of the latter is constituted by the methodology mentioned above. The second case does not mean that the theory of physical education of biological orientation might be situated within the field of biological sciences.

2. Sciences connected with physical rehabilitation, also called physiotherapy, should be situated in the field of biological sciences too.

3. The widely and narrowly understood theory of sport - similarly to widely and narrowly understood theory of tourism and theory of recreation - is mediated through the humanities and biological sciences.

4. By the way, the theory of sport highlighted and the theory of recreation have a common area of content-related interests connected with highly qualified forms of tourism, such as Himalaysm and ocean-going yachting, which are also forms of achievement-oriented, professional or highly qualified sport.

However, these are not content-related issues (that is, the content of particular sciences) I am going to deal with in the following parts of the text - in spite of the fact that they are significant for formal reasons. First of all I will concentrate on methodological issues. 
The abovementioned classification has, in principle, instrumental - not autotelic - character, it is going to help to expose views connected with the general methodology and specialized methodologies concerning physical culture sciences, sports science, kinanthropological sciences and other sciences whose names are used synonymously with the abovementioned names.

In principle, research procedures currently required and employed at the University of Physical Education in Warsaw - shown in methodological schemes of research projects - do not cause much harm, in spite of the fact that in numerous cases they contain incorrect terminology or formal recommendations. This mainly applies to Bachelors and Masters theses, but also - and to a considerable degree - embodies the objectivization of views referring to formal assumptions, that is, to methodological research procedures connected with $\mathrm{PhD}$ theses. I have encountered this many times as a participant in public defenses of doctoral dissertations.

\section{On the need for hypothesis}

Namely, in the abovementioned formal recommendations formulated by a biologist and addressed to authors of Bachelors and Masters theses of empirical and biological character, the need for formulation of a hypothesis is not mentioned at all, whereas, in the case of the humanities it is said that a hypothesis is acceptable in special cases when it is legitimate. This may lead to the conclusion that the hypothesis is some methodological evil, something harmful, something which is to be avoided, that it is used by people who are unaware of the consequences of that not-recommended methodological move and thus an indication of their ignorance.

A similar opinion on that issue has also been publicly expressed by a biologist, who also emphasized that a hypothesis is generally only used in the humanities, which, obviously deprives disciplines functioning in that field of scientific character.

In another case the biologist proclaimed that science only knows the scientific hypothesis and that a mistake is made by those who introduce into research a working hypothesis, a zero hypothesis, etc., since hypotheses of that kind are not scientific. This same biologist also proclaimed - emphasizing the importance of his statement - that besides scientific hypotheses we are also dealing with common-sense hypotheses. A similar opinion was expressed considerably earlier on that subject by Klemens Szaniawski, who proclaimed that the procedure of formulating hypotheses is not limited to science and that it is often used in everyday life in order to explain various facts and events (Szaniawski, 1987, p. 197).

It is thus worth taking the opportunity to explain that all hypotheses used in the research procedure of scientific character (except for ad hoc hypotheses) are scientific hypotheses. This applies to working hypotheses, starting hypotheses, zero ones, primary ones, initial ones, directing ones, gradual ones, auxiliary ones, ad hoc auxiliary ones, bridge ones, futile and true ones, dangerous and safe ones, quite natural and neutral ones, deep ones, strong ones, probabilistic and non-probabilistic (that is, determinist) ones, related ones, false ones, basic ones, psychological ones, metaphysical and materialistic ones, as well as concluding ones (that is, those constituting the effect of definite - completed here and now - research; those which have undergone verification, confirmation, corroboration or modification as those predicting and explaining a given research problem in the best and the fullest way. They all (with the exception of ad hoc ones) are hypotheses of strictly cognitive, strictly scientific character regardless of where they are applied in considerations and the fact that they possess predictive (prospective, previdistic, projecting, foreseeing), nomotetic (explaining) or predicting-nomotetic character.

By the way, there are some controversies accompanying ad hoc auxiliary hypotheses - their three versions $\boldsymbol{a d} \boldsymbol{h o c}_{1}, \boldsymbol{a d} \boldsymbol{h o c}_{2}, \boldsymbol{a d} \boldsymbol{h o c}$ - undermining their strictly scientific character. An interesting debate is also connected - as is shown in the final part of this paper - with cognitive qualities of complete and noncomplete hypotheses, as well as psychological hypotheses. 
The abovementioned hypotheses, initiating, fulfilling and completing the research process may, sooner or later, undergo rejection, invalidation, and falsification. This may be proved by the history of particular specialized branches, for example, biology, physiology, physics, astrophysics, astronomy, chemistry or biochemistry, medicine and even philosophy. Their history is simultaneously the history of the defeat of particular theories, systems, schools, currents; the history of the birth, development and fall of definite paradigms (Kuhn, 1968; Popper, 1977; Lakatos, 1995; Feyerabend, 1970 and 1979), cognitive disasters of such disciplines as astrology or alchemy, and of methodological conceptions - general and detailed ones, empirical and non-empirical ones (Kosiewicz, 1996, pp. 275-289), as well as evidence for the rejection of hypotheses (constituting after all, the foundations of scientific theories). They are - because of their nature conjectures, manifestations of intellectual intuition. This is proved by their context of scientific discovery and context of justification. It is - and it can be - neither sufficient nor exhaustive since such features are characteristic for every hypothesis. In the opposite case a hypothesis would not be a hypothesis.

Knowledge from the field of general methodology developed by specialists from that field cannot be replaced by accidental and non-professional considerations by people who sometimes attempt to transfer their own living or formal experience from the field of specialised methodology of a given science into other sciences, disciplines or branches, without having knowledge of their specificity. For example, some professors of the University of Physical Education in Warsaw from the field of biological sciences not only oppose using hypotheses in their sciences they also impose that viewpoint on representatives of the humanities as well as on people dealing with the theory of sport or the theory of tourism and movement recreation, making them formally confused about the issue of application of a proper research procedure. On one occasion these researchers are overcome by the argumentation of supporters of applying hypotheses while on another occasion they accept the standpoint of some biologists dismissing the need for using it. For that reason, it may be remarked that after studies at universities of physical education some professors from the field of biological sciences surrender unquestioningly to suggestions by some professors of general university provenance and proclaim like them - for example, one of the bio-mechanists - that the hypothesis is not necessary at all. In some sense a victim of such a standpoint is one of the well-known theoreticians of sport in Poland. Once I advised his talented doctoral student to apply a main hypothesis and perhaps two or three gradual hypotheses in his research since his dissertation was to be composed of some parts and concerned, generally speaking, the application of some means of training because of expected results. The doctoral student was also going to explain the reason for possible changes. Thus, the future dissertation required hypotheses of predictive and explanatory character. That was also the viewpoint, which was accepted at the beginning by the thesis supervisor. However, during presentation of his opinion concerning the initiation of doctoral procedures, the abovementioned bio-mechanist - probably (although I do not exclude the possibility that he made a mistake) under the influence of the science studies paradigm of some UPE biologists of general university provenance - stated that hypotheses in scientific work are unnecessary. The theoretician of sport mentioned earlier - without making any attempt to defend his former standpoint agreed. It was rather - as I suppose - evidence of a lack of insight into the field of theory and application of hypothesis in the discussed issue than a conciliatory gesture in the name of avoiding conflict. It is a pity since, because of that the $\mathrm{PhD}$ dissertation will probably lose some of its formal and content-related qualities.

A big surprise was caused by a statement from another biologist (and a statistician too) who some years ago, during the defense of a doctoral dissertation, was trying to persuade people that hypotheses are not used in research concerning cause and effect relations. How did he hit upon that idea? Where did he find a basis for such an opinion? What constituted the source of his heuristic inspiration? This will probably remain his secret forever.

Shortly speaking his opinion is wrong since the hypothesis in the context of the type of explorations in question is in its element - like a fish in water, an owl at dusk or a puss in boots. This refers both to hypotheses of predicting qualities (in other words, projecting, prospective, previdistic ones) - that is, to those foreseeing the possible emergence of definite facts under the influence of a given reason - as well as 
to hypotheses of nomotetic character, explaining, among other things, when, how, with whom and where; as well as taking predicting into account, which simultaneously constitutes an important part of explanation.

Finally, one of the biochemists not only argued that the hypothesis in biological sciences is utterly unnecessary, but - more interestingly - she undermined the legitimacy of dealing with general methodology and specialized methodology during Bachelors, Masters and doctoral studies. She presented that view some years ago during a conference on the curriculum of doctoral studies, arguing among other things that: a) at university faculties she had worked at there were no classes - lectures or seminars - in general methodology or specialized methodology, and that this is the only pattern worth following in this regard; b) that classes of that type and the whole methodological knowledge (general and specialized) can be successfully replaced by direct contact between a student preparing Bachelors, Masters or PhD theses and his/her supervisor.

On the basis of the above arguments it is possible to distinguish three main viewpoints concerning the hypothesis, which have been developed at the Warsaw University of Physical Education:

1. The one approving its application - characteristic for social sciences and the humanities.

2. The one negating the need to use it - characteristic for some representatives of biological sciences.

3. The one representing an indecisive standpoint on the issue - connected mainly with theoreticians of sport and their doctoral students and other assistants.

The fact that the need to use hypotheses is negated by some representatives of biological sciences at the University of Physical Education in Warsaw probably - and perhaps surprisingly - results from a lack of knowledge that those sciences (and, more widely, natural sciences) have, speaking briefly after Ajdukiewicz (1995 a, pp. 287-313), not only idiographic (descriptive) but also nomotetic (that is explanatory) functions (Whewell, 1851; Poincarè, 1908; Jevons, 1860; Kuhn, 1968; Popper, 1977; Lakatos, 1995) connected, among other things, with principles, hypotheses, finding regularities, registering laws (scientific laws concerning nature) and with theories.

For example, Karl Popper - like his great predecessors William Whewell (1847 and 1851) and William Stanley Jevons (1960) - attributed the key role in the development of empirical - and especially natural and biological sciences - to hypotheses. He popularized on the basis of methodology, science studies and philosophy of science - and especially in the field of knowledge of empirical sciences, particularly natural ones - the notion of hypothetism (Krajewski, 1998, pp. 90-91), connected with the hypotheticdeductive theory of development of science "where the key element is not the idea of verification - that is, pointing out truthfulness of propositions in an inductive way - but the idea of falsification; that is, attempts at proving their falseness" (Chmielewski, 2007, p. 361; nota bene, according to Popper, attempts at proving truthfulness are corroboration, whereas verification, unlike corroboration, means proving (not attempts at proving truthfulness).

Hypothetism points out that knowledge of nature is based, first of all, on hypotheses, which - sooner or later (the sooner, the better) - undergo falsification (falsificationism), among other reasons because of the human subject's innate tendency to make mistakes. This constitutes a manifestation of a so-called science game and simultaneously a testimony to the rejection of logical-empiricist theory of science characteristic for neo-positivism; that is, for the Vienna Circle.

It is worth pointing out that Ajdukiewicz, while considering issues connected with methodological types of sciences, discusses the hypothesis issue mainly in the context of empirical sciences and of the associated registering laws, principles, and theories (Ajdukiewicz, 1985 a, pp. 297-306).

By the way, Wilhelm Ostwald - who was close to empiriocriticism, and especially to Ernst Mach's views - proclaimed the idea of science free of hypotheses. He criticized, similar to his more talented colleague, the atomic theory as unnecessary since it went far beyond empirical data. Later Ostwald backed down from that standpoint since he recognized that the atomic theory had been empirically confirmed (Krajewski, 1998, p. 91).

For specialists from the fields of general methodology, science studies, philosophy of science, and particularly philosophy of empirical sciences, it is obvious that hypotheses are applied. That is because of the 
fact that in natural sciences it is necessary to predict future situations (predicting hypothesis) - for example, in an experiment, which may simultaneously constitute confirmation (corroboration, verification) of a nomotetic hypothesis or of an explanatory theory (based on a hypothesis or hypotheses and on principles and registering laws; that is, scientific laws).

The theory of biology and the philosophy of biology contain, among other aspects, not only presentation of laws and regularities characteristic for animate nature, but first of all explanations in the form of a hypothesis explaining, inter alia, why the researched reality is as it is, what changes taking place in it are and why they take place, what cause and effect relations that appear in that field and why they appear.

Thus, why is such a visible departure from a proper research principle - the need to apply hypotheses - supported by some influential representatives of biological (or, more widely, natural) sciences, both within their own milieu as well as outside of it? And why does this not usually meet with any opposition? This happens for at least two basic reasons:

1. Sometimes in empirical research a hypothesis need not appear. This refers first of all to contributory researches, but also (although rarely) to original explorations focused mainly on the description of a previously unknown domain of reality of organic or non-organic character. Hence, a working hypothesis of previdistic qualities sometimes is not introduced into the research since it is difficult to foresee and explain anything when there are no premises. It is not, however, ruled out that the research may be concluded with a hypothesis, which would serve to undertake - on the basis of the gathered and calculated data - an attempt to explain the existing situation, the studied problem, in a conclusive way or to foresee more facts confirming that hypothesis - that is, confirming the explanation and the prediction.

Nota bene, even if in particular empirical research a hypothetical explanation is not formulated, it should - sooner or later - come into existence. It will appear beyond given research, in other texts, in another language, at another time, in another context of justification embracing a greater number of facts, data, or new theoretical assumptions confirmed by empirical research, if the exploration of the definite research problem is continued (for one reason or another) by other people or other teams. That is because of the fact that the basic aim of all empirical sciences - including also natural ones - is, with the exception of idiography, explanation (understanding). The sciences mentioned strive for this through stating regularities by registering laws (scientific laws) and theories. But a precondition for their formulation is just a hypothesis.

2. In biological sciences, especially in particular milieus (this is only my cognitive intuition) there has probably come into being a different, independent research option - of formal (methodological) and content-related character - supported and consolidated by influential figures. It negates the sense of using any hypotheses. Since in given sciences detailed research and methodological criteria - as well as principles of estimation of cognitive values of research results, publications, Bachelors and Masters theses, doctoral and habilitation dissertations or general research achievements during procedures of conferring a professorial degree - are determined only by a given milieu of scientists using such assumptions from the field of a specialized methodology which have been worked out and promoted by it, the belief that methods practiced in that milieu are right will deepen and deepen.

Doubts and self-reflection concerning the need for self-improvement and development of selfknowledge - that is, of theory (and then philosophy) of a given discipline - will appear when traditional, solidified, self-contained specialized methodologies concerning the discussed sciences are confronted, among other things, with assumptions of general methodology and of contemporary science studies. Autarchy as such - including autarchy in biological science - may lead to significant cognitive shortcomings.

I have mentioned above some professors' statements together with commentaries (others I shall present later) in order to point out that a lack of reliable methodological knowledge may lead to misunderstandings, false conclusions and to connected inadequate contexts of justification. 


\section{General methodology and specialized methodology}

I used to draw the attention of students, doctoral students, and consulting friends preparing their habilitation dissertations to the fact that, in his lectures on methodology of science, Ryszard Wójcicki similarly to other authors - writes that while preparing methodological assumptions for one's own work and dissertations one should take into account general methodology and the relations taking place between it and a specialized methodology because:

1. Development of science is determined not only by specialist results, but also by skills of perceiving more general aspects of such results.

2. Associating facts and methodological assumptions belonging to quite separate specialized branches in a skilful way may influence the development of a given discipline and widen content-related and methodological backgrounds since methodological studies are good training, developing the ability to look at problems in one's own scientific discipline from a more general viewpoint.

3. Methodologies of specialized sciences make use of methodological instruments of general methodology, of its vocabulary, categories, notions, conceptions, and theoretical assumptions, in spite of the fact that they are not part of it, that they constitute parts of particular specialized branches. Although specialized methodologies do not belong to general methodology they are quite certainly dependent on it. For example, notions, which we use while developing methodologies of particular formal disciplines belonging to biological (or, more widely, natural) sciences, social sciences, or the humanities, as well as of disciplines from the fields of physical education, theory of training, or physical culture are, to a considerable degree, notions of general methodological character.

4. It makes it possible to avoid a situation which sometimes appears and which is characteristic for specialists in particular sciences who, on their own account and from the very beginning, define general methodological notions or formulate various kinds of statements of general methodological character (Wójcicki, 1982, pp. 9-14, Kosiewicz, 2004, pp. 78-81), which have been worked out by specialists in that field earlier and which are commonly accessible. What I have mentioned - and what Wójcicki writes about - refers not only to undergraduate and doctoral students, but first of all to professors acquainting young academics with the world of science. Some of them clearly neglect that domain of knowledge - that is, studies on general methodology and on relations taking place between it and specialized methodologies - and this is harmful for themselves and for the academic milieu.

One of the member of the relevant dean's commission, who was analyzing as the chairperson of the relevant dean's commission the contents of Masters and Bachelors theses regarding, among other things, formal issues, stated that it was a mistake to use in those texts the term "specialized methodology"; that the notion "methods" /"metodyka"/ should be used instead. Unfortunately she did not provide any justification for that statement.

I retorted then (probably not very successfully) and explained that just nowadays - referring to currently applied assumptions of the general methodology (see among others Wójcicki, 1982; Kmita, 1975; Kamiński, 1981) - a division into the general methodology (which is a philosophical discipline) and specialized methodologies (which refer - as was pointed above - to the first but which constitute only and solely immanent parts of definite specialized disciplines) is used.

I added also that it is true that a notion of "methods of a given science" was used in the past, but that was before the term "specialized methodology" appeared. In the past it was also used by Ajdukiewicz since there was no better term then. On 12 March 1948, during a lecture delivered at a session of the Science Studies Circle of the Polish Society of Friends of Sciences, he proclaimed that in every science we meet "norms concerning conduct while practicing science which goes beyond the methodologist's competences [in the field of general methodology - Kosiewicz] and belong to a specialist's competences. The discipline containing such rules is sometimes (ambiguously) called methods of a given science (Ajdukiewicz, $1985 \mathrm{~b}$, p. 125,1948 , pp. $4-15)$. 
In the 1970s that term was completely rejected on the grounds of the general methodology dealing also with specialized methodologies, since it was not very precise and too ambiguous. It could be excessively associated with pedagogy and its sub-disciplines. By this I mean, among other things, a part of pedagogy called methods, dealing with ways of teaching and methods of physical education constituting a subdiscipline the of theory of physical education. That is also the reason why at universities of physical education the term "methods" should not be used instead of "specialized methodology".

And if, in spite of that, somebody liked to use just that term, first she/he would have to present a justification referring among others to the abovementioned argument. If she/he did not do it, it would arouse a suspicion of methodological ignorance. And, on the other hand, if she/he explained why she/he had done it, it would also expose them to the accusation of a minor vice - for example, that the author is a freak specialist keen on unnecessary methodological archaisms. I think it is simpler - as far as both the author and the reader are concerned - to use the notion of specialized methodology.

\section{Empirical research and problem-related research?}

One of the Vice Deans of the UPE in Warsaw also recommends a quite specific division of Bachelors and Masters dissertations into empirical and problem-related work. The first group was to concern, as was suggested by this Vice Dean, first of all biological (or, more widely, natural sciences) and research referring to them, while the latter - theoretical fields (which is to say: social sciences and the humanities). Nota bene, I do not know of any serious professional methodological text pointing out the legitimacy of such a standpoint.

That is because all research and scientific dissertations have a problem-related character. The research problem has to be included in the subject of the research and in the title of more or less serious scientific dissertations as well as Bachelors and Masters theses. They are to be presented (explicitly or implicitly) with the aim of the undertaken research as well as with possible gradual aims referring to the main aim. The realization of the aim and the research problem strictly correspond to questions about gathering proper data constituting the basis for solving a given problem. Hypotheses foresee and explain issues concerning a given research problem. Their confirmation, negation, or possible modification, are served by general and particular methodological assumptions of one's own research. For that reason, the division proposed by the abovementioned Vice-Dean and the connected suggestions are, unfortunately, inappropriate and unfortunately mislead students and academics who trust the author.

The proposed division pointing out an opposition between empirical sciences on the one hand, and social sciences and the humanities on the other, is neither complete nor sufficient since within the area of empirical sciences there are conducted strictly theoretical research, research from the field of the humanities, and formal research. For example, in biological sciences we distinguish, except for in strictly empirical investigations, the theory of biology, the philosophy of biology, historical research referring to the history of that science as well as formal dissertations concerning general and particular methodological assumptions of given sciences.

Moreover, empirical research connected with striving for achievement of assumed aposteriorical results, is based on theoretical and terminological assumptions characteristic for a comprehensively accepted research convention. It usually constitutes their extremely developed part.

Nota bene, within the field of physical culture sciences distinctions are made (this has never been an esoteric mystery) between the humanities - such as, among others, philosophy, history, psychology, pedagogy, theory of physical education or sociology. The first two are clearly non-empirical, while the others if they focus their attention on their own histories, on strictly theoretical researches, or on specialized methodology have in those fields a character which is also typically non-empirical. An example in that regard may be Prof. Zbigniew Krawczyk's "Selected Works" constituting a part of the monograph edited on the occasion of his $75^{\text {th }}$ birthday ("Sport, Culture, and Society" 2005, pp. 21-149; "Sport, kultura, społeczeństwo" 2006, pp. 23-198). From among all his empirical and non-empirical publications Prof. Krawczyk selected only theoretical texts. The others have considerably lost - in his own opinion - their 
cognitive value. Their qualities, which primarily seemed to be universal, have passed. The arguments included and data of inductive character appeared to be - colloquially speaking - past their sell-by date.

\section{What do we know about verification?}

Basic methodological mistakes constitute, however, a considerably issue which does not only concern people working at the University of Physical Education in Warsaw. I will make use only of an example from the Lublin Catholic University. In the review of Stanisław Srebro's doctoral dissertation on “Józef Tischner's Conception of Social Life" I wrote that the author uses the notion of verification in a colloquial meaning as a synonym for checking. I also (briefly) pointed out that in general methodology - referring, among other things to neo-positivist assumptions and Anglo-American methodology and philosophy of science (Wittgenstein, 1922; Lewis, 1934; Nagel, 1934; Popper, 1935; Stace, 1935; Carnap, 1935 and 1969, p. 68, 70-79, 1973, pp. 840-851; Schlick, 1936; Reichenbach, 1936; Bryman, 2004; Gratton i Jones, 2005) that verification means the same as confirmation of the logical value (truthfulness or falsity in the logical sense) of statements, hypotheses, registering laws (scientific laws) or theories, and, moreover, that the abovementioned checking is called in general methodology - and in specialized methodologies referring to it - testing or testification, and not verification. The notion of verification in the meaning pointed out by me by is used by, among others, Klemens Szaniawski (1987, pp. 197-206), Władysław Krajewski (1998, pp. 9597) and Stanisław Kamiński (1981, e.g. pp.142-143).

As a response, the doctoral student pointed out that understanding the notion of verification as a synonym for checking "is, however, present, in the classic philosophy (Więckowski, 1983, p. 420), but it is not the only one, since verification may mean also confirmation; that is, proving truthfulness of theses" ("Mały słownik terminów i pojęć filozoficznych" /"Small Dictionary of Philosophical Terms and Notions" 2000, col. 924). Neither meaning of the term contradicts the other and both are used in philosophical literature, especially in the area of Christian philosophy.

In a commentary on that explanation I may remark that general methodology comes, after all, from formal sciences, from logic and mathematics. Ajdukiewicz emphasises - while considering metamethodological background in the field of considerations on research procedures - that mathematical, and even meta-mathematical - roots are characteristic not only for methodology of apriorical sciences (deductive ones), but also those of the humanities (among others, of philosophy of mathematics, or philosophy of science). The connection is in the latter case obvious - at least, regarding logic of induction. It is, after all, closely connected with mathematics (Ajdukiewicz, 1985b, pp. 117-126). Connections between induction and mathematics were described by, among others, by John Stuart Mill (1962) and Imre Lakatos in works dedicated to the philosophy of empirical sciences. The latter pointed out that the aim of inductive logic is determining the probability of various theories regarding all accessible empirical data. If mathematical probability of a theory is high, it has scientific character (Lakatos, 1995, p. 355).

Halina Mortimer (1987, p. 221) proclaims among other things that logic of induction is connected with such logical rules of reasoning which enable to distinguish among forms of inductive reasoning between such forms of reasoning which are methodologically correct (justifying, rational) and those which are incorrect (in spite of the fact that those forms of reasoning do not have deductive character, and only deductive reasoning gives a complete guarantee of truthfulness of conclusions when truthfulness of premises is assumed).

Pointing to the fact that nowadays verification is understood in general methodology as confirmation we should remember that in the 1930s it was only the "Vienna Circle" (the name was proposed by Carnap, 1969 , p. 68) where the scientific argument concerning the notion of verification was initiated. Nota bene, the thesis on verifiability was formulated firstly by Ludwig Wittgenstein (1922; Carnap, 1969, p. 68) cooperating with that circle - that is, with the creators and proponents of neo-positivism (called, among others, scientific, empiricism). Namely, in the period in question there was proposed - and then rejected - a 
controversial distinction between notions of verification and confirmation, as well as the distinction between notions of verification and checking (testing), accepted and rooted in general methodology.

Verification constituted for Carnap the complete and final determination of truthfulness - that is, of the abovementioned logical value of an examined statement or complex of statements of empirical character from the field of natural sciences. From that viewpoint he regarded universal propositions - for example, laws of physics or biology - to be propositions, which are not subject to verification.

It follows from that that the notion of verification as the final effect of detailed confirmations was referred by him only to registering laws; that is, to scientific laws. Nota bene, if such a meaning is assumed, final verification never takes place. Carnap pointed out (1973, p. 848) that that notion was shared also by Popper (1935), who - in Carnap's opinion - had emphasized in detail and explained the impossibility of absolute verification, as was confirmed by conceptions of falsification and fallibilism. Carnap was also of the opinion (ibid) that his viewpoint was in complete conformity with standpoints of Nagel (1934, p. 144) and Lewis who is the author of the most detailed analysis and criticism of the requirement of verifiability (1934). Lewis maintained, among others, that "Knowledge which is expressed by the majority of commonly accepted propositions may never been verified with absolute certainty and definitely" (Lewis, 1934, p. 137). Nota bene, the aim of a more detailed explanation of the thesis on verifiability of scientific laws and hypotheses was undertaken by Moritz Schlick (1936), who responded to Lewis's critical remarks (Carnap, 1973, p. 843).

Confirmation, on the other hand, concerns - according to Carnap - particular elements constituting the law; that is, hypotheses explaining and foreseeing particular facts. Although justification of that distinction is not explicitly presented by Carnap, it is clear that such a thought appears in his argument accompanying that idea. Namely, we read that if we can never exhaust - that is, grasp - the whole, all cases connected with our research, we cannot finally and completely verify the law. We may only "test it by testing its particular cases; that is, particular propositions which are derived by us from the law and from other, previously substantiated, propositions. If in the course of following checking efforts we do not find any negative case and the number of positive cases found by us grows, our belief that the tested law is correct grows. Thus, rather than verification we may speak here about gradually growing confirmation of the law" (Carnap, 1973, pp. 846-847).

It follows from the abovementioned argument that Carnap thinks that the notion of verifiability is reserved solely for hypotheses. Thus, partial verifications are individual, particular or gradual confirmations, and the possible complete and final confirmation of truthfulness of a scientific law - which, on the basis of what is proclaimed by Carnap, seems impossible - is simply verification. It follows from that that verification may not come into existence, that it is completely absent and must be absent in natural sciences; that what may exist is only confirmability and confirmation of particular propositions, hypotheses constituting a scientific law or derived from it. Such a distinction is not, however, legitimate since - as Carnap writes - it is, nevertheless, possible to "assume verifiability of each single case of a given law" (1973, p. 846). If this is so, it may be assumed that confirmation - that is, partial or gradual verification may lead to the final verification. Hence - even in the context of that what is proclaimed by Carnap - both partial and complete confirmation may be called verification. Nowadays verification as a partial confirmation is called confirmation or corroboration. On the other hand, the final stage of confirmation is called verification. This is contradictory neither to Carnap's, nor with Wittgenstein's. Schlick's, Lewis', Popper's and Nagel's methodological conceptions.

Krajewski points out that in methodological literature the notion of verification means - referring to Latin etymology - proving truthfulness. He confirms also that in methodological literature there is used also a notion of confirmation of a hypothesis, if its consequences have been empirically confirmed (Krajewski, 1995, p. 96). It is thus worth pointing out differences which take place between particular terms concerning confirmation. Thus, unlike verification, which means proving (complete or partial) truthfulness, 
confirmation is evidence of a high degree of reliability and probability. Hence, confirmation may be described as probabilistic verification.

Besides that, in the Anglo-American literature the word corroboration is used, which was introduced and promoted on methodological foundations by Karl Popper, and which, in Polish literature, is written "korroboracja" and is used as a synonym for the term "potwierdzanie". Confirmation is translated as "potwierdzenie".

That subtle distinction has significant logical and methodological consequences. Hence, the procedure of confirmation of a hypothesis should be described with the notion of "corroboration", whereas the final result of those endeavours, if they have been successful, should be called verification.

By the way, Krajewski's interpretation of Popper's notion of verification has become popular. Nevertheless, it is worth pointing out that Popper introduced the idea of corroboration or level of corroboration in order to prove that every probabilistic theory of induction, that every probabilistic hypothesis, is nonsensical. He understands the level of corroboration of theories (and hypotheses) as a concise report evaluating the state of critical discussion on them, taking into account the way they solve their cognitive problems, levels of their verifiability, difficulty of tests they have passed, and the way they have survived those tests. As he writes: "Corroboration (or degree of corroboration) is thus an evaluating report of past performance" (emphasis added by me, (Popper, 1992, p. 31)). I would like to return to Stanisław Srebro's statement, where he pointed out that the notion of verification and the notion of checking may be recognized as synonymous. I would like to remind readers that in neo-positivist literature those notions were treated as separate and autonomous ones of different contents. Thus, Carnap, who agreed in that respect with Schlick, gives a relevant example. He writes that in order to check the course of rivers they are observed with measuring instruments and on that basis the logical value of the proposition "Rivers flow upwards" is confirmed or negated - that is checked. In the first case, when all observed rivers flow upwards, we are dealing with verification; that is, with the final confirmation of truthfulness of the postulated proposition. With every single case (concerning a given river which flows upwards) we are dealing with an individual confirmation; that is, with a partial - and not the final - verification (Carnap, 1973, p. 844). Carnap writes then that in order to make a physical hypothesis confirmed, "some checking observations should be made" (Ibid, p. 848). Thus, it follows from the above fragment that he (like Schlick and, after him other methodologists) differentiates clearly and consistently between verification and checking (testing).

The above arguments have been presented in order to point out the formal basis of general methodology. Because of that its interpretations are independent of any factor or influence connected with world-view or ideology (for example, Marxism or Catholicism). There does not exist - and there cannot exist - any interpretation of that kind in the field of general methodology since it may not be, similar to mathematics or logic, Catholic, bourgeois or socialist. Their basis is constituted by the only one general and basic interpretation - namely, formal assumptions independent of emotional, world-view-related and ideological norms. They may not interfere with any content-related context of justification.

Catholic philosophy of theology is a science because its specialized methodologies strictly correspond to and refer to assumptions of general methodology. If it, or other specialized disciplines, pass over those assumptions they will finally place themselves beyond truth or falsity in the logical sense and, hence, beyond rational science - for example, statements of religious character, mystical, mythical, or mythological messages or saints' writings.

Commenting on Srebro's statement on verification and checking, it may be added that the notion of verification as a synonym for "checking" or "having checked" (without any differentiation) appears, unfortunately, not only in "classic philosophy" and not only "in the area of Christian philosophy", but also in various non-denominational philosophies; independent, on principle, of the influence of any world-viewrelated or ideological assumptions. Its mistaken - that is, colloquial and hence non-methodological understanding and application have, unfortunately, become popular and are present even in the 
abovementioned philosophical dictionary. I have found that just in that meaning it is used by some recognized Polish philosophers. The abovementioned doctoral student (now a doctor) also contributed to making that viewpoint popular and undermined, on that occasion, the authority of Christian philosophy as such.

The notion of verification (connected with notions of confirmation and corroboration), and the notion of testing in a meaning which has been given by me - and which is characteristic for general methodology - are defined in different ways. They may overlap when, as a result of testing (checking), statements are confirmed, that is, verified. The notion of testing is wider than the notion of verification (or confirmation, or corroboration), because it includes both the possibility of confirmation as well as falsification. Hence, it is worth knowing that each of those notions is underpinned by different theoretical assumptions and that each of them serves different practical aims.

In the discussed case, methodological consciousness has been extremely strongly influenced by colloquial ways of thinking. It has contributed to the emergence of surprising terms. There have appeared such expressions as "positive verification" or "negative verification". Hence, there has come into being - in the light of methodology (taking into account the viewpoint of the quoted doctoral student) - a troublesome and difficult cognitive and formal problem.

That is because in that respect (in the colloquial sense) we are dealing: firstly, with a positive effect of testing, and secondly, with a negative effect of testing. Trouble appears when we consider the contents of those expressions in the light of strictly methodological principles. For example, verification may be treated both as a procedure enabling confirmation (corroboration), as well as the final effect of that.

But the expression "positive verification" sounds bizarre in the logical sense since it informs us that the confirmation (verification, corroboration) we were striving for - and which, for obvious formal, that is, logical reasons, means a positive effect - is positive. This comes from the sense, meaning, and contents of the expression "positive verification". In logic that type of semantic fact is called a pleonasm. In a given case it is enough to use a term verification (or corroboration) as confirmation of the procedure which is discussed or the final confirmation of effects of its application - that is, assumptions, hypotheses, etc. which have been assumed earlier. Summarizing our considerations regarding the different notions referring to confirmation, it may be said that the term verification describes an aspiration for confirmation, the term corroboration means the procedure associated with the aspiration for confirmation, and the term confirmation describes the final confirmation of the hypothesis.

From that viewpoint Józef Herbut's argument - concerning the two types of interpretation of scientific theory and indicated with the expression "a positive form of verification" - is completely incomprehensible. This refers to the second type of scientific theory, which is presented below and which enables the theory to acquire (because of that term and the connected evaluation) a higher cognitive rank. It (the theory) appears thanks to a confirmation of a hypothesis on the strength of which it transforms into a scientific law.

Herbut (2003, p. 488) writes that

"The relation between (general) hypotheses and scientific theories is described in two ways: the name of the theory is given either to a system composed only of hypotheses (in simple cases: one hypothesis) serving to explain a given field in a comprehensive way, or to a system of defined notions, laws and hypotheses - comprehensively explaining a given field; that second definition of the theory is given by those methodologists who are proponents of the positive forms of verification (emphasis added), and who proclaim that a general proposition built on theoretical terms ceases to be - if it has been confirmed to a high degree - a hypothesis and achieves a rank of a scientific law".

The expression highlighted in the quotation is surprising because in the text - which, nota bene, is dedicated to the hypothesis - the abovementioned author, while discussing the issue of testing the hypothesis (which constitutes a significant fragment of the discussed text) nowhere identifies the notion of testing with the notion of verification. Nor does he explain how he understands that verification. It follows from his 
statement that testing logical values of the hypothesis is treated by him autonomously; that is, independently of verification. However, there is no explanation for why he has applied the notion of verification in a given place. We may only suppose that probably the notion of verification was used unintentionally in a colloquial meaning and that this significant negligence has been corrected neither during the author's, nor the editor's revision. This unfortunately lowers the cognitive rank not only of the quoted fragment but of the whole statement which, in every other respect, is well-prepared. It is not known whether the author in using an expression "a positive form of verification" has in mind a positive form of confirmation ("positive verification") or a positive form of testing, or something else. The first case concerns a content-related deficiency, which has been discussed above, as well as logical properties of a pleonasm. The second case is not so much about the effect of testing but rather about an evaluation of its method, that is, form - a positive form. However, the second possible interpretation of the commented expression does not correspond to the contents of the message at all. Other possible interpretations or different understandings are impenetrable for me.

On the other hand, in the case of the expression "negative verification", a clear internal logical contradiction is present in it. Namely, verification as such - that is, because of the meaning of that term may not be negative. It possesses in a formal sense - both as striving for cognition (for example, in PseudoPlato's definition and according to the interpretation of Neo-Platonists referring to Aristotle that striving is a realization of the need to come as near to the epistemological Absolute as is possible for the human being, (Domański, 1996, pp. 3-8; Pseudo-Platon, 1973), as well as its effect - only a positive value. Thus, it does not possess a negative value. I emphasize once again, verification - both as realization (corroboration), and also as the final result of research procedures - always has a positive and never a negative value. In the case when striving for corroboration is not successful, we are dealing with a failure of research - that is, with falsification of the assumed statements, assumptions, aims, hypotheses, etc. We are never dealing with negative verification.

Hence, the abovementioned statement by Dr. Stanisław Srebro - proclaiming that the two meanings of the term verification (verification as confirmation and verification as testing) do not contradict each other - is a logical and methodological mistake leading to misunderstandings.

Moreover, if in general methodology the term testing is used as a synonym for checking, there is no need to add one more substitution in the form of the term verification, which is, after all, ascribed with a different meaning in general methodology and specialized methodologies - and with many other meanings according to its colloquial interpretation. It would be useful to accept - not only for logical or methodological reasons, but also for clearly pragmatic ones - and use in science and in research when statements, assumptions, principles, hypotheses, theories, disciplines, smaller or bigger scientific paradigms are discussed, the three abovementioned terms of different meanings: verification (as proof of truthfulness, taking into account independent confirmation and corroboration), testing (as checking or testification) and falsification (as rejection, negation - that is, questioning, disconfirmation (Carnap's term - Carnap, 1973, p. 848, as well as elimination, invalidation, refutation or disproof, Lakatos's terms - Lakatos, 1995, p. 377). On that basis (if a proper research procedure is applied) it is possible to determine a logical value of statements existing or appearing in science in a clear and rational way (as was predicted in the abovementioned methodology) - that is, to state if they are true, or false in the logical sense (there is no third possibility).

In the case of the discussed issue, mixing up the methodological order and the colloquial language order also leads to the appearance of language curiosities in everyday life. For example, during martial law (introduced in Poland in December 1981), so-called verification of staff of various state institutions was carried out for extreme political and ideological purposes. As a matter of fact, it was neither checking usefulness, nor confirmation of particular persons' ability to function in a new situation after the imposition of the abovementioned law, but a well-organized "cleansing" that is, firing political opponents, firing opponents of the then government, and adherents of the "Solidarity" movement. Thus, those actions and their results were, as a matter of fact, obvious falsification of political opponents' usefulness for work in state 
institutions. Its effect was not only dismissals from work but often imprisonment or forced emigration. Nevertheless, in the consciousness of the Poles who did not distinguish the methodological order from the colloquial language order, there has remained an association uniting the notion of verification with rejection, negation, and falsification. However, it - that is, such an effect in the form of colloquial collective conclusion - need not be a determinant of a definition or of an expert opinion in the field of general methodology. The latter rejects that type of external influences, the influence of colloquial thinking - it consistently sticks to the initial assumption and to the definition formulated on that basis, which proclaims that the notion of verification means final confirmation, also taking into account terms and differentiations connected with confirmation and corroboration, which are significant from the methodological viewpoint. That notion should in no case be treated as a synonym for testing or falsification. It should also not appear in such pairings as "positive verification" or "negative verification".

During one of the sessions of the University of Physical Education Senate Commission of Science (the last one in 2007) there was discussed the final, as had seemed earlier, proposal on the list concerning scoring various research achievements. However, it turned out that it had to be changed after another suggestion by the Polish Ministry of Science and University Education. Hence, one of the participants proclaimed that, "The list must be verified". There thus appeared another colloquial meaning of verification, which came into being in a circle of representatives of science and which was far from its methodological meaning. Verification, according to that colloquial interpretation, concerned solely a "change". "To be verified" was to mean the same as "to be changed"; that is, modified or falsified, in order to make a given list anew then.

On the other hand, in one of the therapeutic-pharmacological statements concerning the application of a medicine we read: "Duration of treatment depends on the scale and place of pathological changes. If there is no improvement after three or four weeks, the diagnosis should be verified".

In that interpretation a colloquial and not very clear meaning of the notion of verification has again been applied. Clearly a requirement constituting its context does not suggest confirmation that the diagnosis is correct. The expression mentioned and the accompanying context clearly point to an incorrect evaluation of the real state of affairs - that is, of symptoms and reasons of pathological changes. The expression "to verify the diagnosis," means in that case "to change the diagnosis" - that is, either reject (negate, falsify) it as improper, or to modify it, or to apply a quite new one. The procedure of checking the diagnosis as such (that is, checking it and nothing else) generally may not be taken into account, if in a given case it has proved to be inappropriate, if several weeks of empirical - that is, pharmacological - testing of it has failed.

It follows from the abovementioned examples (it would be possible to point to many others) that the notion of verification is too broad ranging. In its colloquial interpretation it includes many different, sometimes mutually exclusive, meanings. From that viewpoint it follows that introducing them into methodology or into research procedures is not advisable since this could be the cause of significant misunderstandings and cognitive mistakes.

\section{Hypothesis beyond resentment - a theoretical interpretation}

\section{Principle and convention}

Further considerations on the hypothesis require us initially to turn our attention at least to issues concerning formulation of the research problem; that is, to the principle, the aim - or aims - of exploration, since they condition (similarly as research questions, material, and methods) its exposition and contents, kind and shape, as well as the way of examining the logical value of a given hypothesis. Their discussion will probably not contribute to the development of the theory of hypothesis as such, but it will surely enable to synthesize knowledge of it and, as a result, to transmit it to students, doctoral students, doctors working on their habilitations (and to their supervisors), which may be useful in better preparing Bachelors, Masters and doctoral dissertations, as well as habilitation monographs, for their defense (and possible partial or complete publication). 
Formulation of the research problem is aimed at full, detailed discussion of the central content-related issue in Bachelors or Masters theses, or in more serious research work (in the plan its presentation has a sketchy character and during the realization of the task the abovementioned formulation of the research problem becomes considerably enriched and broadened). It consists of characterizing, presenting the significance of a given problem, and describing its place in subject-related literature. Hence, various viewpoints, earlier and current solutions and interpretations of a given problem, are introduced. On that occasion - which is especially important for teleology of a given undertaking - the cognitive and research deficits, the need for starting and continuing the planned scientific exploration, as well as the fact of whether the research has original, contributory, or synthetic character, are highlighted. It implies and becomes integrated into the context justifying the basic aim of the undertaking (as well as the relevant gradual aims).

Proper (in the content-related and methodological sense) formulation of the research problem is a necessary precondition for application and the proper formulation of the working hypothesis (etc.), as well as gradual and other aims connected with the realized procedure (this also refers to principles, possible regularities, and registering laws). It also requires defining if the existing - big or small - scientific paradigm characteristic for a given discipline is used or new content-related and methodological solutions are introduced. Thus, it obliges the identification of definite theories to which it refers, as well as the clear indication of which notions, terms and the connected definitions will constitute the basis of the research procedure. Hence, you should provide information on which type of research convention is used and which non-empirical postulates, also called assumptions, are applied, for example, in research of inductive character.

Hence, Ajdukiewicz introduces the notion of principles. He uses it to describe terms specific to empirical science, which have exactly the character of the abovementioned postulates determining the meaning of those terms (Ajdukiewicz, 1985a, s. 304).

Stanisław Kamiński distinguishes after Karl G. Hempel two kinds of principles: a) those characterizing basic objects and processes (their existence is assumed by the theory, but they are impossible to be observed or measured directly), b) those pointing out connections between those basic processes and empirical phenomena - those already given or those which can be foreseen (Kamiński, 1981, p. 197).

It was conventionalism - one of the more important currents distinguished in methodology, science studies and philosophy of science - which turned attention to the presence of principles within the field of empirical sciences. It takes its name from the fact that it emphasizes the conventional character of principles as postulates establishing meanings of terms, which can be presented in the form in which they have been explicated or quite differently, depending on the definition and the connected argumentation - that is, depending on the proposed convention. The main representative of conventionalism was a French philosopher of science, expert in science, and methodologist Henri Poincarè (Ajdukiewicz, 1985a, p. 304; Dąmbska, 1975; Krajewski, 1972; Poincarè, 1908 and 1911; Siemianowski, 1983 and 1987, pp. 322-330).

Andrzej Siemianowski writes that, according to Poincarè, conventionalism is a current, which treats axioms of theories in mathematics and natural sciences as conventions. Those conventions are by no means pictures of the real world, but only useful practical instruments (Siemianowski, 1987, p. 324).

Poincarè was of the opinion, as is pointed out by Ajdukiewicz, that not all statements belonging to empirical sciences are directly or indirectly based on experience (which did not constitute for the eminent Frenchman an obstacle to maintaining that the real "scientific method is based on observing and experimenting" (Poincarè, 1911, p. 1). There may appear in them - obviously - terms taken from apriorical sciences, for example, arithmetic or geometry, which are used in a way by empirical sciences (Poincarè, 1908, pp. 117-132).

"There exist, however, statements specific to particular empirical sciences, which have not been borrowed from anywhere. They include especially synthetic definitions and their consequences. Ajdukiewicz points out (1985a, p. 302) that the statement that water under the normal pressure boils at a temperature of 100 degrees Celsius is only a logical consequence of the definition of 
the term 'a temperature of 100 degrees Celsius'. Such apriorical statements seemingly referring to empirical knowledge are - according to David Hume - notions of the cause and effect relation, the substance and the power".

Hume was of the opinion that experience does not qualify us to state that there are cause-and-effect relations of material character. He criticized the belief in the existence of essence and power (Hume, 1947, pp. 67-77). This refers also to the notion of the magnetic or electromagnetic field, the law of inertia, the law of momentum and impulse.

The abovementioned conventionalism - which took on a "normal" form [coming from Poincarè and Pierre Duhem - an eminent historian of science, especially medieval science (Duhem, 1906)], or a radical form [connected with Ajdukiewicz, who then took a stance of extreme empiricism, and with Ludwig Fleck (1986)] - points out than not only principles, but also scientific theories we have assumed and their consequences are effects of scientists' agreement - that is, of conventions of methodological and contentrelated (that is, formal or apriorical, or deductive, as well as empirical; that is, aposteriorical, experiencebased or inductive; and humanities character.

Poincarè, basing his arguments on this, undermined the belief in the empirical value of scientific knowledge, since the latter is composed not only of laws, which register coexistence or co-dependence of facts and are generalizations of observations, but also - as is pointed out by Stanisław Kamiński - of principles, that is, of general hypothetical proposition of huge explanatory force, but impossible to be directly empirically verified or confirmed. Only the assumption of additional propositions - a convention, that is, a bridge hypothesis, enables us to refer it (that is, those additional propositions) to data given by experience. The choice of just that hypothesis is guided neither by logic, nor by experience, but it is suggested to us by intuition and invention on the basis of conventional language arrangements. Thus, scientific theories do not reconstruct reality they concern only its structural regularities since they are its translation into a conventionalized language. Hence those theories and hypotheses constitute a system of symbols, which make it easier to work out data of an inductive character. Those empirical data, as dependent on a language convention, need not fulfill the criterion of truth, but those of simplicity, convenience, and aesthetics. In spite of that - according to Kamiński - science as such has first of all theoretical, not practical value (Kamiński, 1981, p. 142).

The conventionalism discussed above may be compared with or interpreted from the viewpoint of the conception of small and big cognitive paradigms (according to Thomas Kuhn's (Kuhn, 1969) interpretation). From that standpoint principles are a small paradigm, that is, a convention of shorter range. Whereas assumptions which are worked out for the use of planned research, and which refer (often controversially because of the range of their usefulness) to various theories, terms, definitions, and postulates (including principles), may be called a bigger paradigm, that is, a convention of a longer range, which constitutes a necessary theoretical introduction and a necessary context of justification for initiated and continued exploration.

The abovementioned conventions are applied to realize the aim of the work. It comes directly from the subject (the title of a Bachelors, a Masters, a doctoral, a habilitation or a professorial dissertation), as well as from the scientific research problem formulated for a unit or a team of some research institute. Thus, there is a close connection between the problem and the aim of the research (and the connected gradual aims) on the one hand, and the applied theoretical and methodological convention on the other.

Hence, in the part dedicated to the aim of the work there may appear not only suggestions (information) regarding researched material and methodology of the research, but also more or less developed information about expected results. This refers mainly to what you want to describe, new facts which are expected and what you want to explain with the help of the abovementioned principles, regularities, and laws, as well as possible hypotheses, which are the most important aspect from the viewpoint of the presented text. 


\section{Considerations on hypothesis}

The hypothesis - as is indicated by Latin etymology (hypothesis, suppositio, coniectura) - is an assumption, supposition, conjecture, basis, or premise. It is treated as a provisional answer to some question or (treating it more narrowly) the question "why?" as a statement assumed provisionally for cognitive or practical reasons (Herbut, 2003, p. 487). That statement is initially and ultimately treated as a true one in spite of the fact that its truthfulness has not been determined yet - that is, it has been neither partially nor ultimately confirmed or verified depending on the abovementioned viewpoint. According to Klemens Szaniawski, the hypothesis is a supposition put forward on a trial basis "in order to explain the observed phenomena or established regularities, as well as to foresee facts which have not been observed before. In that sense, all general knowledge is hypothetical, except of logical and mathematical truths without empirical contents" (Szaniawski, 1987, p. 206).

He adds a similar-sounding supplement postulating epistemological and methodological caution in the realm of cognitive procedures and recommends avoiding entanglement in controversial issues. Hence, he states that, "it is possible at the most to proclaim in general terms that hypotheses are suppositions aimed at explaining and foreseeing. Thus, because of the suppositional character of empirical knowledge, hypotheses ubiquitous in science" (ibid).

Kamiński, on the other hand, proclaims that limits of knowledge are determined by everyday life cognition. Science is elaboration of common sense knowledge. It derives from it its first principles and then only generalizes them. However, the researcher exploring phenomena is not entirely passive. Naked facts are necessary but simultaneously insufficient empirical material since empiricism as such - that is, pure empiricism - is cognitively heuristically entirely fruitless. Thus, a directing hypothesis is needed, which would show experience the way to discover laws and, finally, to perform reasoning. Only the discovery of a real - static or dynamic - connection between phenomena makes it possible to explain them and to foresee one on the grounds of another (Kamiński, 1981, p. 84).

Hypotheses are, according to the Lublin philosopher and methodologist, creative propositions on a supposed state of affairs, which has not been observed and is not able to be described with known laws. There are propositions which explain (together with other theses) given facts or which axiomatically define some theoretical term (Kamiński, 1981, p. 195).

\section{Hypothesis in formal sciences - in mathematics}

The hypothesis was present in ancient Greek mathematics (arithmetic and geometry). It was probably adopted from dialectics characteristic for the Greek discussion with a thesis - that is, a scientific argument on a given subject. That thesis - or hypothesis - constituted a common starting point, a statement assumed by everybody, or the basis of a philosophical or a mathematical argument, since this was the time when mathematics was part of the one science called philosophy.

The term "hypothesis" was used in mathematics as a term for unproved principia-axioms from which the detailed theorems were deduced; a classic example of such a kind of hypothesis are the axioms of Euclidean geometry (Herbut, 203, p. 487).

Ajdukiewicz, while proclaiming his opinion on properties of axioms in the deductive system, points out when such a system may become a hypothetic-deductive system. He writes that the

"character of the axiom is attributed to a proposition not because of a level of its certainty, but

because of the role which is played by it in a deductive system. An axiom of a deductive system may be any proposition. However, the character of the axioms determines the character of all other propositions belonging to a deductive system. If obvious certainties are assumed as axioms, then theorems of the system as deductive sentences - that is, derived from certainties in a sure way - become reliable sentences. If axioms are only statements - for example, only generalizations formulated through incomplete induction - theorems are no more reliable than 
axioms (for example, some systems of theoretical physics have character of such theoretical systems). Axioms may be also statements somehow suspended in the air, which are neither recognized, nor rejected, but which have character of suppositions. Then theorems do not draw any certainty from those entirely neutral axioms (systems of such axioms are called hypothetic-deductive systems)" (Ajdukiewicz, 1985a, pp. 292-293, emphasis added).

It is Ajdukiewicz's statement (from 1938) concerning the relation between the hypothesis and formal sciences (mathematics). His methodological and philosophical considerations on hypothesis are mainly focused on empirical sciences and examples from the field of natural sciences since when they were formulated by him he was a representative of the then extreme empiricism.

Henryk Poincarè, continuing a traditional dispute between aprioricism and empiricism concerning assumptions of mathematics remarked, as is reported by Stanisław Kamiński, that they neither come from experience nor are a priori necessary - as is proved by the existence of various equally legitimate geometries. According to Poincarè, there takes place the third situation pointing out that assumptions of mathematics constitute conventional hypotheses assumed by the mind. They are not required - writes Kamiński - to be true. It is enough that they are simple and convenient for mathematicians when working in some field and that as a consequence they prove to be the most beneficial for mankind (Kamiński, 1981, p. 142).

\section{Hypothesis in empirical - natural sciences}

\section{a) Hypothesis from Poincarè's standpoint}

Henryk Poincarè, who was considering the place and the role of hypothesis in natural sciences at the beginning of the previous century, stated that it is every generalization which is present in their field and which should "be testified as quickly as possible and as often as possible" (Poincarè, 1908, p. 125). Success is not confirmation of a hypothesis - it may also be its invalidation. The second case does not necessarily mean that we were dealing with a fruitless hypothesis since its heuristic consequences may be even more valuable than those of a hypothesis which has been confirmed (it may do "greater favours that a true hypothesis" (ibid, p. 126)).

The French philosopher of science distinguished dangerous hypotheses, which appear on the foundation of initial and advanced research procedures. "They are - in his opinion - first of all and more than anything else - tacit and unconscious hypotheses" (ibid), which we cannot get rid of because in a given research situation we are unaware of their existence. Mathematical physics is helpful in that respect since it makes explicit all empirical hypotheses.

Besides that, Poincarè distinguishes three categories of safe hypotheses: a) quite natural hypotheses which are unavoidable, b) neutral hypotheses, and c) hypotheses as real generalizations.

An example of the first category are hypotheses concerning nature, which are impossible to be passed over or not formulated since "it is difficult not to suppose that the influence of distant bodies may be entirely passed over, that small movements are subject to linear laws, that a result is a function of its reason" (ibid).

An example of the second category of the hypothesis, that is, of the neutral hypothesis, may be an effect of research by an analyst who

"at the beginning of his calculation supposes that matter is either continuous, or, quite the opposite, is composed of atoms. If he assumes not one of these assumptions but the opposite, that would not change his results at all - at the most, his calculations would be longer and more difficult" (ibid, p. 127).

There are, in this quotation, two mutually exclusive neutral hypotheses: a) a hypothesis that matter is continuous and b) a hypothesis that matter is composed of atoms. Which of them is true and which of them is false is entirely insoluble by experience (Siemianowski, 1987, p.329). 
Siemianowski, commenting on Poincarè's views, points out that all neutral hypotheses have a metaphorical sense. The scientist may not completely abandon metaphors. However, she/he must be aware of their value. Indubitably they are useful in an instrumental sense "as a means of facilitating calculation or supporting our reason with particular images" (images).

Hypotheses of the third category are subject to confirmation and invalidation by experience. Confirmed or rejected "they may always be fruitful (...) a precondition for that fruitfulness is that they are not too numerous" (ibid, pp. 127-128). Hypotheses should not be multiplied without testing. They should be checked for their logical value one after the other, since we may bring about the emergence of an improper and disadvantageous cognitive situation.

"For - as Poincarè proclaims - if we build a theory based on multiple hypotheses, we will not know which of the premises should be changed when experience invalidates it. And vice versa: when an experiment is successful, will it confirm all hypotheses together? Is one equation able to define several unknowns?" (ibid, p. 126).

\section{b) Hypothesis and facts}

Those historical and cognitively inspiring reflections about the hypothesis in natural sciences have served contemporary methodologists for further research and findings in the characterized field.

Ajdukiewicz confirms that one of the principal tasks of empirical sciences - and especially of natural ones - is explaining facts with hypotheses and theories; that is, facts directly empirically experienced and general regularities formulated in registering (scientific) laws. An explanation of a given fact is an answer to the question of why a given fact takes place. However, if we want to explain some fact found by experience or a registering law, we may find ourselves in a troublesome situation if we do not notice any theorem among those already assumed from which the proposition stating that fact would logically result. Thus, explanation of that fact with the help of already-existing theorems would be impossible. In such a situation as is pointed out by Ajdukiewicz - we assume on a trial basis (that is, as a supposition) some new theorem, which is such that it enables us to explain the fact - that is, a proposition stating the fact logically results from that theorem and from some other already assumed laws. If that theorem is not a general theorem with particular cases directly found by experience, if it is not a registering law, than that theorem assumed to explain the facts will be called a hypothesis (Ajdukiewicz, 1985a, pp. 300-301).

The range of hypotheses in empirical sciences is, as Stanisław Mazierski proclaims, very long. They may be connected with looking for the existence of objects, the structure of the object, the quality of things, or with connections between objects, regularities taking place in nature, casual (cause and effect) relations, or sequences of phenomena. The hypothesis usually replaces absent observational data, to say nothing of its other functions. Thanks to hypotheses, we go beyond existing knowledge, go from known to unknown objects and proclaim our opinions about relations between them (Mazierski, 1993, p. 87).

"Thus, on the foundation of already-assumed theorems $\mathrm{P}$ hypothesis is some $\mathrm{H}$ theorem" - writes $\mathrm{M}$ -

"which is neither directly based on experience, nor registers results of the hitherto observations,

but it has been assumed on that basis that with help of the $H$ theorem and the $P$ theorems it is possible to explain some facts found by experience or some registering laws, which would be impossible to be explained with only the P theorems and without assuming the H' (ibid, p. 301).

The hypothesis constitutes not only an explanation of the fact which has already happened, but it may also serve to explain some other facts, if it constitutes - with the assumed scientific laws - a logical reason for them. Each such new fact, which is explicable by a hypothesis is its new confirmation and increases its probability - the more so, the less it was expected (Ajdukiewicz, 1985a, pp. 300-301).

Hence, Szaniawski says that there appears a question of the so-called strong hypothesis, which enables us to foresee previously unobserved phenomena. They are also easier to test (Szaniawski, 1987, p.198). 
According to Krajewski, who supplemented Ajdukiewicz's statement, a specific situation takes place when there appear facts, which contradict already-existing theories. These are anomalies, or - in other words - anomalic facts. After their possible identification a new hypothesis is formulated in order to explain those facts. However, it cannot be directly testified. It is necessary to derive from it its empirical consequences in a deductive way - that is, to foresee facts, which, according to that hypothesis, must come into existence. Then it is necessary to carry out testing with observations or experiments.

\section{c) Auxiliary hypothesis and ad hoc hypothesis}

Ajdukiewicz - criticising conventionalism and, at the same time, approving of the research program of Popper's hypothetism and logical empiricism - formulated a conception of an auxiliary hypothesis (which is different in the content-related sense from the auxiliary hypothesis according to Latatos's interpretation, which is presented below). According to the Polish methodologist, only theorems of logic and other analytical propositions constitute auxiliary hypotheses subject to empirical control together with natural hypotheses (based on facts). By the way, that conception of testing the auxiliary hypothesis together with the natural hypothesis corresponds with an earlier idea of Pierre Duhem's holistic empiricism, since its author proclaimed that in physics not one particular proposition but whole systems of propositions are tested (Duhem, 1904; Siemianowski, 1987, p. 328).

On the other hand, when a hypothesis explains and foresees only one phenomenon, we are dealing according to Krajewski (1998, p. 141) - with an ad hoc hypothesis, which is not highly appreciated in science.

Imre Lakatos compares that hypothesis - that is, the ad hoc hypothesis - to empty ruses, maintaining appearances and linguistic tricks. He states that, according to Karl Popper, saving theories threatened with falsification with help of auxiliary hypotheses meeting some well defined conditions constitutes scientific progress. On the other hand, saving theories (composed, among other things, of hypotheses) with the help of auxiliary hypotheses, which do not meet such conditions means degradation. It is only Popper who calls such auxiliary hypotheses ad hoc hypotheses, simple linguistic ruses. and conventionalist tricks (Lakatos, 1995, pp. 46-47). And although they - according to William Whewell (1847) in his commentary on Isaac Newton's theory of light - "truly express facts [they were to explain], they have not been confirmed by any other phenomena" (Lakatos, 1995, p. 58). Hence, Popper introduces a principle of avoiding ad hoc ruses into the criteria of evaluating scientific hypotheses (ibid). After falsification of one hypothesis another is introduced. However, it has to correspond to its predecessor, that is, it must "explain a partial success of the earlier hypothesis (if that has taken place), and to add something more. A hypothesis, regardless of its intuitive and innovative aspects, may not be accepted if it does not have new empirical contents in comparison with its predecessor. If there is no surplus of the contents, the reviewer will call it " $a d$ hoc" and make the author withdraw it. If a new hypothesis does not have ad hoc character, it is subject to standard procedure applied to falsified hypotheses" (ibid, p. 241).

Lakatos distinguishes "three types of auxiliary ad hoc hypotheses: those which do not display any increase in empirical contents, "corroborative surplus", if compared to its predecessor or rival - that is those, which do not foresee any new facts ("ad hoc,"); those which have such surplus contents, which have foreseen new facts, but which have completely failed and nothing of the increased contents has been confirmed ("ad hoc"); and those which are ad hoc in both those senses, but which are not positive heuristics in both those senses ("ad hoc 3 ") (...) A part of cancerous development in contemporary social "sciences" is constituted - also according to his opinion - by a spider's web of "ad hoc 3 " hypotheses.

The Hungarian-American methodologist and philosopher of science writes that examples of the types of hypotheses mentioned are provided by linguistic ruses by pseudo-scientists or conventionalist tricks, like "excluding freaks", "excluding exceptions", "adjusting freaks", etc. A famous example of the "ad hoc 2 hypothesis is Fitzgerald-Lorentz's hypothesis of contraction. An example of ad hoc 3 hypothesis is the first amendment introduced by Max Planck into the Lummer-Pringsheim formula (ibid. pp. 145 and 187-188). 
Apart from ad hoc auxiliary hypotheses, there are distinguished also such auxiliary hypotheses which serve protecting a theory, and especially its hard core, from alleged counter-evidence which could falsify it. Hence, a protective zone of auxiliary hypotheses is created, which serves repelling negative influences of one test after the other. It must be constantly adjusted, modified, increased, and complicated in order to defend the core of a theory, which is hardened that way. The hard core remains intact. Anomalies are not treated as invalidation of the hard core of the research program, but as rejection of some hypotheses in the protective zone of auxiliary hypotheses (ibid, pp. 73-75 and 304).

It happens that a hypothesis is rejected and then is saved by an auxiliary hypothesis, which is not an ad hoc hypothesis according to any of the abovementioned interpretations (senses). It may foresee new facts, which later on are even partly confirmed. Lakatos suggests in that regard - that is, while using auxiliary hypotheses - precision and coherence. He warns against latitude since it happens that it is possible to achieve a kind of pseudo-progress with a series of tangled, random, and disconnected hypotheses and theories. Good scientists will not be satisfied with such progress. They may even reject it, saying that it is not authentically scientific. They will call such auxiliary hypotheses only "formal", (pseudo-formal), "arbitral", "empirical" (pseudo-empirical), "half-empirical" and even "ad hoc" ones.

Mature science - Lakatos concludes - is composed of research programs constituting frameworks where not only new facts, but also new hypotheses and auxiliary theories are foreseen. In positive heuristics of a strong research program (without provisional activity of ad hoc qualities) there exists a general outline of how to construct protective zones (composed of auxiliary hypotheses) from the very beginning.

That conclusion points out weaknesses of two - seemingly very different - types of research programs. Firstly, it proves weakness of programs which, like Marxism and Freudism, are indubitably "uniform", which give a basic outline of kinds of hypotheses and auxiliary theories they are going to use in order to absorb anomalies, which invariably devise their hypotheses and auxiliary theories in the face of facts, and which simultaneously do not foresee other facts (nota bene, what new facts have been foreseen by Marxism since 1917?). Secondly, it strikes at tangled, uninventive, prosaic "empirical" amendments, which are so numerous, for example, in contemporary social psychology. Such amendments may, with the help of so-called "statistical techniques", make some "new" predictions, and even conjure up in them some unimportant grains of truth. Such cognitive endeavors lack, however, the uniting idea, heuristic power, and continuity. Such hypotheses and theories do not constitute an authentic research program and, as a whole, they are worthless (Lakatos, 1995, pp.145-147).

Evaluation of the research program takes a lot of time since - according to a sentence characteristic for Hegel's philosophy of philosophy (meta-philosophy) - Minerva's owl flies only at dusk. That evaluation requires not only the research program to foresee new facts, but also the protective zone of auxiliary hypotheses to be constructed to a considerable degree according to the unifying idea, which has been assumed earlier and which was stated beforehand in positive heuristics of the program (ibid, s. 252).

Popper - unlike Lakatos - and according to his own conception of falsificationism - is of the opinion that auxiliary hypotheses are ones that when introduced do not decrease the degree of falsifiability or testability of a given system, but - quite the opposite - increases it. Their application must always be treated as an attempt to construct a new system, which can be evaluated from the viewpoint of constituting by it possible real progress in knowledge of the world (Popper, 1977, p. 71). Nevertheless, the name of a scientific hypothesis is deserved - according to Ajdukiewicz (who, criticizing severely his earlier conventionalism, came closer to falsificationism) - only by one, which may be definitely invalidated by giving strict evidence of its falsity (Siemianowski, p. 328).

\section{d) Probabilistic hypothesis as an explanation or lack of it}

Evaluation of the research program depends also on the fact of whether it includes propositions of probabilistic contents - that is, probabilistic hypotheses. Szaniawski points out that there exists such a view that probabilistic hypotheses explain nothing, that their proper function would be prediction (formulation of 
statements about an object, about its definite property or relation), that the notion of explanation based on the relation of logical explaining is inapplicable to propositions of probabilistic content (nota bene, the notion based on the relation of logical concluding is called the deterministic - that is, non-probabilistic hypothesis. A proper example in that regard may be the paradox of a lottery.

Carnap maintains that the probabilistic hypothesis may never be fully verified, that only its gradual confirmation is possible. The degree of confirmation of the hypothesis may be interpreted as the level of probability in such a strict meaning, which is had by that notion in the probability calculus, that is, as a limit of relative frequency.

According to Carnap this is how the issue is presented by Hans Reichenbach (1936, p. 154pp.). However, Reichenbach did not work out such a kind of interpretation in a detailed way and it is doubtful whether such an interpretation is possible at all. Difficulties, which are met by a frequent attempt at interpreting the degree of confirmation, were emphasized by Popper (1935, charter VIII). The main difficulty, according to him, consists of the fact that it is not known how to define for a given hypothesis a set of related hypotheses, that is, those hypotheses the notion of frequency is relativised to and which, if confirmed, would heighten the degree of probability of that probabilistic hypothesis - that is, the hypothesis constituting the cognitive axis of the research program. "It seems to me" - Carnap writes - "that it still is not clear if the notion of the degree of confirmation is possible to be defined as a quantitative notion - that is, as a numerical quantity - at all" (Carnap 1973, pp. 849-850).

Szaniawski points out that in the case of probabilistic hypotheses, there are no decisive data. For that reason, the decision to accept or reject a hypothesis must be based on the probability of mistakes and on their relative significance. Thus, testification of hypotheses is connected with a calculated risk. Principles of that calculation are differentiated. They are dependent on the assumed conception and interpretation of probability. If probability is understood in a frequential way, it is hardly ever justifiable to point out the probability of the hypothesis both before and after doing the test (Szaniawski, 1987, p. 202).

A pessimistic cognitive undertone of the probabilistic hypothesis has been tried to be weakened many times. Attention - apart from Carl G. Hempel's postulates (1945, 1962, 1965, 1968; Mortimer, 1987, pp. 223-225), and others modifying the probabilistic rule in order to make confirmation and acceptance of hypotheses dependent on other introduced factors different than probability - is deserved, among others, by I. Levi's probabilistic rule. It is founded on cognitive utility of the hypothesis and on the connected criteria of its measurement referring, inter alia, to diversity of content or information or the simplicity or extent of explained phenomena. The aim of the hypothesis - similar to that of science as such - is the reduction of ignorance.

For that reason a set of basic hypotheses, which are to constitute an exhaustive set of theorems explaining a given research problem is created. They all have an equal as well as the greatest possible amount of content - that is, an equal value regarding reduction of ignorance. Levi postulates rejection of basic hypotheses of probability, which is too small if compared with the content. However, it is possible to accept a hypothesis of small probability if it is more probable than the rival hypotheses. He excludes, moreover, rejection of all basic hypotheses even if their probability is close to zero thereby neutralizing the paradox of the lottery. Hence, accepting a basic hypothesis is, on the one hand, positively dependent on the degree of probability and, on the other hand - unlike the probabilistic rule - not only dependent on probability, since acceptance of a hypothesis is dependent here also on the content (Mortimer 1987, p. 224).

\section{e) Statistical induction and hypothesis}

A hypothesis of probabilistic qualities is something we also encounter in reasoning characteristic for statistical induction. A conclusion which has come into being on its foundations and concerns a definite statistical property of some population, may be a hypothesis assuming, for example, that the probability of the presence of the researched feature in the population is high. 
Hence, two different actions are applied (within the range of statistical induction) to a hypothesis, which has come into being in such a way - namely, testification of hypotheses and estimation of parameters. The first of them consists of creating or singling out such a hypothesis, which is called a zero hypothesis. A test applied to it is understood as a decision aimed beforehand at rejecting it. By the way, the zero hypothesis is treated outside statistical induction as a starting hypothesis, an initial one, etc.

On the other hand, estimation of parameters consists of the choice of the most proper hypothesis (concerning a definite - desired from the viewpoint of that exploratory procedure - quality, that is, an estimator) - the hypothesis which, of all possible hypotheses referring just to the parameter in question is the closest to its value. On the basis of estimation, the difference between the real value of a given parameter in the population and the value calculated on the basis of the sample is estimated. That difference is called the size of the mistake. However, we do not single out mistakes of the first and the second kind characteristic for the procedure of testing hypotheses within the range that is pointed out below.

Testing hypothesis within the range of reasoning characteristic for statistical induction is required to have such a zero hypothesis that makes it possible to calculate the probability of a mistake consisting of its rejection when the hypothesis is true. Such a mistake is called the mistake of the first kind and its probability - determined on the basis of a long series of detailed tests - is defined as a level of significance for a test.

An effect of the discussed testing may be also the mistake of the second kind - consisting of the fact that the zero hypothesis has not been rejected when it is false. The probability of avoiding that mistake is called the power of a test.

However, the mistake of the second kind - and, hence, the power of a test, are not always possible to calculate. In spite of that, there exist some possibilities of comparing definite tests regarding their power (Mortimer, 1987, pp. 220-221).

\section{f) Cognitive and formal status of the complete and the incomplete hypothesis}

An opinion about probabilistic hypotheses was also formulated - although implicitly - by Ajdukiewicz (1985, pp. 301-302), who maintained that every new fact which has been foreseen by the hypothesis increases its probability. Maybe that outstanding methodologist's statement was rather about confirming again - that is, strengthening - the context of justification (truthfulness) of a given hypothesis, than about probability resulting from statistical data or probabilistic theories. Nevertheless, the abovementioned conclusion initiated a quite significant - methodological and with regard to science studies - argument in the field of the theory of hypothesis concerning the complete hypothesis and the incomplete hypothesis. Nota bene, they could also be regarded - though this was not done by Ajdukiewicz - from the viewpoint of relations which have been presented (and characterized above) by Carnap and other representatives of neo-positivism, and which take place between the verified hypothesis (whose truthfulness has been completely and finally established) and the hypothesis which is gradually, partially, or individually confirmed.

It is worth pointing out once again - especially with reference to arguments of scientific empiricists (a notion used by Carnap as a synonym for the notion of the Vienna Circle) and Ajdukiewicz's statement - that the hypothesis as such - that is, regarding incomplete explanation (which is indispensable and necessary from the viewpoint of its species-being) - is always an incomplete hypothesis (in a different meaning than that presented by Ajdukiewicz), that its context of justification has greater or smaller gaps, spheres of ignorance and suppositions. This is because of the fact that the hypothesis is a conjecture that is never fully confirmed. It is intuitive cognition - that is, that form of intuition that is called intellectual intuition. When the sphere of knowledge, of factual data is widened the sphere of suppositions may be diminished or completely neutralized. If all necessary data and facts provided and explained by a given hypothesis appear, the hypothesis thus loses its formal status completely and transforms into a registering (scientific) law. From that viewpoint the hypothesis is always incomplete. When it explains in the complete - that is, maximal - 
way, it may not transform into a complete hypothesis but only into a scientific law. Thus, the hypothesis always occurs in the form of an incomplete supposition - that is, an incomplete hypothesis.

Ajdukiewicz is of the opinion that the incomplete hypothesis refers to the explanation which

"admittedly, does not lead to the explained fact as a conclusion, but if such an explaining statement is assumed, that fact becomes more probable. In many cases we are satisfied with assuming hypotheses explaining facts only in an incomplete way" (ibid, p. 302).

He compares juxtaposing the complete hypothesis with the incomplete hypothesis to juxtaposing general registering laws with statistical laws. He proclaims that particular cases of the general registering law result logically from that law. On the other hand, that statistical law makes only those particular cases more or less probable (ibid).

However, this is a disputable standpoint since it is assumed - as pointed above by Szaniawski - that probabilistic hypotheses, based on assumptions characteristic for the theory of probability, based solely on statistical data, do not explain anything and, hence, from the explanatory viewpoint they are neither complete nor incomplete. On the other hand, the registering law also is not a complete hypothesis because it is a scientific law not a hypothesis. In the formal sense that conclusion is basically irrefutable.

\section{g) Three interpretations of the psychological hypothesis}

In methodological literature concerning natural sciences (including biology) we find also a notion of the psychological hypothesis (it is used also by Lakatos - 1995, pp. 322-326).

That hypothesis may be regarded among others in three ways: a) in relation to the researcher's psychological experiences - that is, introduced on the basis of individual and subjective cognitive data which are characteristic only for him/her, b) in relation to researched persons, derived from their associations, and c) in a relation which associates - that is, synthesizes - the two abovementioned viewpoints.

An example of the first interpretation may be a researcher taking into account the possible probability of two or more mutually competing hypotheses and having at his or her disposal similar rules or procedures of their testing - the researcher choosing from among them a hypothesis and a rule. Admittedly, freedom of choice of the rule and the hypothesis is limited by some principles of rationality, but it is impossible to be completely eliminated. Hence, a non-rational - subjective, psychological - factor appears as a measure of belief in the truthfulness of the hypothesis as a sense of the rule and the reliability of the research procedure. A hypothesis burdened with such a psychological belief is the psychological hypothesis, which is probable or true because of a given person. As a result of testing, the probability of the hypothesis is usually changed - it is increased or diminished (Szaniawski, 1987, pp. 198-202). A hypothesis of that type, or a greater number of them, may - according to Lakatos (1995, pp. 322-326) - be placed in the protective belt of auxiliary hypotheses around the hard core of the research program.

The second understanding of the psychological hypothesis is connected among others with the discovery of the reasons of puerperal fever by Ignaz Semmelweis in 1847. One of the rejected hypotheses had a strictly psychological character. The Hungarian doctor supposed that the appearance of the illness in the maternity ward might have been facilitated by terror felt by women who heard the sound of the bell preceding the arrival of the priest with the last sacrament (Krajewski, 1998, pp. 94-95).

The third interpretation of the psychological hypotheses is connected with taking into account and combining into the whole the two abovementioned viewpoints. That type of the hypothesis comes into being as a result of psychological experiences of the researchers and persons who are researched by him or her, or of the population the research refers to, for example, in An Enquiry Concerning Human Understanding (Hume 1947). The English extreme empiricist - and, simultaneously, a proponent of anti-inductionism pointed out that experience, as an instrument of research, does not give certain knowledge. He was of the opinion that empirical procedures, inductive reasoning, cannot be considered in the light of truth and falsity in the logical sense. That is because of the fact that formal logic cannot constitute a basis legitimizing 
cognition based on extraspection perceiving the external world and nature. It is insufficient. Induction and the connected reasoning are completely incompatible with logic.

Considering cause-and-effect relations, Hume writes that "we are ignorant, it is true, of the manner in which bodies operate on each other" (Hume, 1974, p. 157), and that we are not "able to comprehend any force or power by which the cause operates, or any connection between it and its supposed effect" (ibid, $p$. 158). Some repeated event or facts are united by us into cause-and-effect relations because of the fact that there is just such a kind of inclination in our minds; that is, an inborn associating desire.

Hume writes that that relation experienced by our mind, "this customary transition of the imagination from one object to its usual attendant, is the sentiment or impression from which we form the idea of power or necessary connection" (ibid, p. 159). Thus, he is of the opinion that the cause-and-effect relation is solely a psychological hypothesis; that is, in that case, inductive reasoning including generalization which, admittedly, is referred to reality, but its source is only (a given researcher's) individual and subjective habit and a custom resulting from inborn associational determinants (characteristic for all subjects of a given population) inducing association of observed causes and results into cause-and-effect relations.

Thus, it may be supposed that hypotheses establishing cause-and-effect relation are - according to Hume - psychological hypotheses determined by associative properties of the human subject. Nota bene, a current in psychology called associationism - which came into being over a century and a half after the publication of Hume's Treatise of Human Nature (1740) and An Enquiry Concerning Human Understanding (1748) in England - perceives Hume as its precursor. Thus, an extraspective view referring to cause-andeffect phenomena is a psychological hypothesis which can be neither rejected, nor proved, since it is beyond human cognitive abilities (agnosticism).

Concluding the above part of the paper, it may be added that the psychological hypothesis based on premises of inductive character is an explanation and, simultaneously, a prediction based on immanent subject-related and subjective associational mechanisms.

\section{h) Individual and general hypothesis and phenomena inaccessible to direct observation}

The hypothesis may be an individual or a general supposition. Individual hypotheses - according to Herbut - perform neither the explanatory nor the predictive function. They are formulated in order to obtain an answer to a question about some facts (for example, "what is the distance between the Moon and the Earth?" (Herbut, 2003, p. 487). An example of that type of hypothesis is also the Pythagoreans' view who first supposed that the Earth is concave or convex, and later that it is round and has the shape of a sphere. The last hypothesis was confirmed by sailors - great discoverers - and became a registering law, a scientific law.

Herbut's view is, however, disputable, because it is relatively easy to find an example of the individual hypothesis of explanatory (nomotetic) character. It is, among other things, a statement that the axis of the Earth circumscribes the side of the cone. This has been assumed to explain backward movement of equinoctial points (Ajdukiewicz, 1985, p. 301). Hence, contrary to Herbut's statements (2003, pp. 487488), the individual hypothesis performs the explanatory function (it may be treated as a deep hypothesis) in spite of the fact that it does not perform a predictive function.

On the other hand, an example of the general hypothesis (that is, of the empirically general hypothesis) is a statement pointing out that particles of each electrolyte dissolve in solutions into ions (because electrolytic dissociation takes place). The hypothesis of that type has a "law generating" character, meaning that its full confirmation leads to the establishment of a registering law - that is, a scientific law.

In the last two examples - concerning the general hypothesis and the individual hypothesis - we are dealing with an explanation, which has not been based on data resulting directly from experience. They simultaneously constitute examples of the deep hypothesis. 
Besides hypotheses referring directly to facts, there are also distinguished hypotheses of qualitative character, concerning hidden reasons and internal mechanisms of phenomena, which are inaccessible to direct observation. These are deep hypotheses. Their name comes from the fact that they refer to the "depth" of reality, the essence of processes, which are empirically cognized. An example in that respect may be the cognitive activity of Isaac Newton, who explained the phenomenon of the rainbow by pointing out the complex character of white light. This also refers to the hypothesis pointing out that light consists of crosswise waving - initially it was supposed that it results from qualities of ether, and then, thanks to Maxwell, from the influence of the electromagnetic field, which enabled scientists to explain the phenomenon of diffraction of light, interference, polarization, etc. It was also explained that sound is connected with longitudinal waving of air (or another atmosphere), which enabled also the explanation of a number of phenomena connected with its travelling. It was explained also that heat results from inertial, the massive movement of molecules, enabling the explanation of thermal expansion, thermal conduction, and many other phenomena. There are many more examples of that type (Krajewski, 1998, pp. 101-103).

\section{i) Birth of hypothesis, context of scientific discovery and context of justification}

The formulation of a hypothesis is a creative process. It is not subject to any rules, canons or regulations. All ideas are permissible - those, which are seemingly the most fantastical and unexpected lead to the solution of the problem. The process of creation of the hypothesis, especially of the deep one, is far removed from the process of logical reasoning. It is based on intuition and constitutes a result of a peculiar illumination illuminating the dark space of cognition. However, it is based also on great knowledge and experience connected with the researched field and it happens - as was proclaimed by Louis Pasteur - only to properly prepared minds (ibid, p. 148).

Such may be a hypothetical context of scientific discovery - that is, the context preceding and inspiring the birth of the hypothesis, which may be assumed on the basis of little or vague data, or intuitive and even non-rational premises. On the other hand, the context of justification of the hypotheses (that is, the theoretical foundation of its sense) must be strictly rational and consistent from logical, methodological, and content-related viewpoints. Formulation of such a context is accompanied by a strictly formal procedure. Just from that viewpoint - as well as from the viewpoint of cognitive assumptions - that context, as well as the very hypothesis (its predictive and explanatory qualities) are evaluated.

That context may include - and (as Krajewski remarks) usually does include - various additional assumptions constituting the "background" of a given hypothesis, which Popper calls background knowledge (ibid., p. 129; Popper 1992, p. 100).

As Kamiński writes after M. R. Cohen and Ernest Nagel, creation of the context of justification of the hypothesis should take into account the following rules of conduct:

First - sufficient autonomy and order should be maintained. This means that the principles of proper autonomy of justification and its independence from other fields of cognition, as well as of methodical character and accuracy connected with rules of conduct and precision of the language, should be observed.

Second - it is necessary to look for the most final premises in a given scientific branch and use them as the basis. In empirical sciences those premises, which are specific to them, can only be constantly controlled results of observation or reliable evidence. You should not refer to authorities treated as infallible or the final criteria for deciding, in spite of the fact that it is appropriate to take into account opinions of authoritative persons - rationally recognized experts. Kamiński emphasizes that during recognition confirmation of statements - having absolute trust in intuition and, especially referring to so-called halfobvious facts - may be dangerous. That is because intellectual intuition must be rationally prepared in a proper way, concern the proper object, and also must be subject to indirect control by rules of the language.

Third - impartiality (objectivity, disinterestedness, independence from ideas assumed in advance) and versatility, i.e. readiness for taking into account all sensible possibilities in the procedure of choosing ratios, 
should be maintained. In the last case, it is not about being influenced by scepticizm treated as a principle, but about an attitude, which is helpful for removing possible mistakes or shortcomings in the process of justification and creation of science and of widening knowledge. Kamiński adds that logical certainty - that is, reliability and irrefutability - are rarely achieved. However, this is always about epistemological certainty - that is, providing logically valuable arguments ensuring justifiability of assumed hypotheses in the strongest possible way. The process of systematizing statements should be mainly aimed at making directly justified propositions as few as possible because reasoning is more easily controlled (Kamiński, 1981, pp. 194-195).

\section{j) Working hypothesis from the teleological viewpoint}

The abovementioned initial suppositions formulated at the beginning of the research procedure are called working (zero, primary, initial, introducing) hypotheses. They have a twofold cognitive aim to achieve.

First, it is assumed that they serve, in the teleological sense, the formulation of the final hypothesis on their basis. The latter explains as fully as is possible - or predicts as accurately as is possible - possible future facts. It may be preceded by stage hypotheses (partial hypotheses), if a definite research program provides for it - which is connected with the level of complication of the project and with stage aims which are necessary for that reason and indispensable for realization of the task. The final hypothesis - similarly to particular stage hypotheses - can be verified, confirmed, corroborated, or modified in a way either strengthening or diminishing its cognitive value. The optimal diminishment of its cognitive value leads to its falsification.

According to Alan Bryman (2004, p. 400), working hypotheses are hypothetical explanations of the research question. As a result of testing data and examining cases, there are accepted cases confirming the hypothesis and there are rejected deviant cases not confirming the hypothetical explanation. The effect of this is a transformation, reformulation, or modification of the hypothesis, or an explanation based solely on confirmed cases, data, and facts. That conception should be compared with Chris Gratton and Ian Jones's suggestions (2005, pp. 26-27, pp. 31-37).

Second, it is possible to aim at the falsification of the existing hypothesis - which assumes, for example, a positive influence of a pharmaceutical inconsistent with at least one case - right away. Success of the endeavor aimed at rejection of the hypothesis, which allegedly explains the influence of the drug in the right way, is in a given situation a significant cognitive - and simultaneously practical - achievement, which is important from the social viewpoint. It rejects the preceding results of the research, pointing out a mistake included in the explanation and predictions. It inspires possible subsequent empirical inquiries. However, the most important result of falsification is preventing possible negative health-related results.

A hypothesis or an empirical theory is regarded as falsified only when a repeated event invalidating it is discovered (refutation, disproof). In other words - maintains Popper - we accept falsification only when a lower-level empirical hypothesis which describes such a phenomenon (and then explains it) is formulated and then verified. The hypothesis of that type is called the falsifying hypothesis. Admittedly, it may be characterized by a low level of universality, but it must be an inter-subjectively verifiable proposition. In order to falsify a proposition proclaiming that "all ravens are black", an inter-subjectively verifiable (and not universal) proposition pointing out that a family of white ravens lives in the New York Zoo is enough (Popper, 1977, p. 74-75).

Besides consciously striving, on the one hand, for verification, confirmation, and corroboration of a given hypothesis and, on the other hand, for its falsification, we may also check - that is, test - a hypothesis. This happens when we do not know its logical value - whether it is true or false. As a result of the undertaken attempt, we decide whether it is true or not. 
Herbut is of the opinion that from the logical viewpoint the aim is to derive logical consequences from the tested hypothesis (usually in conjunction with other statements) and to find out if they are true or false. Pointing out at least one false proposition among consequences of the hypothesis is called its falsification. If all consequences of the hypothesis prove to be true, it is proclaimed that the hypothesis has been verified, confirmed, or corroborated to some degree (Herbut, 1973, p. 488).

Secondly, according to Popper, the hypothesis is formulated in order to reject it as quickly as possible (falsificationism). From that viewpoint, the hypothesis has a pragmatic and conventional character because it is only a provisional explanation giving a temporary benefit and advantage doomed to failure that is, to falsification - from the outset.

Popper was of the opinion that progress in science does not consist of accumulating experimentally confirmed results, since he rejected cumulativism as a theory and as a real manifestation of the development of science. He thought that progress is an effect of invalidation - that is, falsification - of hitherto hypotheses. He argued that it consists also of replacing them with more daring hypotheses, including more information that has a greater cognitive value - for example, with hypotheses explaining various facts and regularities which have not been connected so far in a creative way. Hence, he was an anti-cumulativist, similar to Kuhn (1968), Lakatos (1990 and 1995), Poincarè (1908 and 1911) and other proponents of conventionalism, or Feyerabend - the main representative of methodological anarchism (1970 and 1979). He strengthened assumptions of falsificationism with the conception of fallibilism, which is not only about an endeavor to invalidate the hypothesis empirically, but also the belief that every scientific theory is questionable, uncertain, and unstable. This results in juxtaposing some hypotheses with others in order to eliminate them. It requires the constant creation of new hypotheses, which are an alternative to the rejected ones (Kawalec, 2003, pp. 484-485).

\section{k) The hypothetic-deductive procedure in natural sciences}

Krajewski presents five elements of the hypothetic-deductive procedure characteristic for proceeding empirically in natural sciences. These are: a) identification of facts requiring explanation, b) formulation of an explaining hypothesis, c) deriving its empirical consequences (deduction), d) testing based on observation or experiment - that is, confrontation of those consequences with facts, and e) the conclusion: recognition (partial confirmation, confirmation, verification) of the hypothesis or its rejection, falsification (ibid., pp. 9293).

Herbut, while proclaiming his opinion on the issue of the hypothesis in empirical sciences (aposteriorical, inductive, experimental sciences), and especially in natural sciences, confirms that contemporarily there are created "law-generating" hypotheses; that is, hypotheses in the form of general propositions (that is, general hypotheses and, in that case, empirically general hypotheses) describing some regularities of states of affairs - e.g. proclaiming that planets are in elliptical orbits. They gain the status of natural laws if they are confirmed strongly enough. Sometimes hypotheses are also formulated about individual states of affairs (individual hypotheses). After their confirmation they transform into individual empirical propositions - e.g. that there exists the planet Neptune.

The general empirical hypothesis in natural sciences should meet four conditions: a) it should be consistent with the empirical propositions constituting the basis on which it has been formulated, b) it should be harmonious with theoretical knowledge which has already been achieved in a given field, c) it must not be semantically empty; that is, it must have content enriching a given field of knowledge, and d) it must be basically verifiable (Herbut, 2003, p. 487).

Nota bene, that last condition - contrary to what is proclaimed by Herbut - cannot be met in all cases. Hence, only the small quantifier is applicable. For example, in natural sciences - and especially in cosmogony - hypotheses are formulated concerning the beginning and the possible end of the universe. Both in the first and the second case hypotheses may not be "basically verifiable". This does not mean that you 
should not strive for testing them. However, in the case in question - as well as probably in many others (for example in the field of anthropogenesis) - their final testification will not take place.

To the conditions for the general empirical hypothesis, which have been mentioned above by Herbut, Krajewski adds two more. He points out that such a hypothesis should also be: a) simple, if it is possible (being aware of the fact that there are various criteria of simplicity, and b) heuristically inspiring; that is, its explanatory and predictive power should be as great as possible - it should explain and predict as many facts as its possible (Krajewski, 1998, p.141).

Herbut while characterizing the main functions of the empirical hypothesis in natural sciences points out its explanatory and predictive properties. The first kind are based on other theoretical propositions which have been already assumed; that is, on additional assumptions, which - as pointed out above - Popper (and later Krajewski) calls the "background" or the "background knowledge" of a given hypothesis. The hypothesis, which has such properties explains some facts (or laws of a lower level) which have not been explained yet or provides an explanation which is different from the hitherto assumed one. On the other hand, the predictive function refers to predicting new facts or truths.

As we can guess, Herbut does not talk in that case about functions of hypotheses in empirical sciences, but first of all about functions of the general hypothesis in natural sciences (I emphasize general), since this is the only one which has both explanatory and predictive properties, unlike the individual hypotheses discussed above (Herbut, 2003, p. 487). Nota bene, the division of functions of hypotheses proposed by Herbut is senseless, especially when their explanatory functions are closely connected with the prediction, and prediction is a necessary element of the explanation of facts that have come into being in nature.

\section{Hypothesis in the humanities}

The hypothesis in the humanities has a wider range of questions than in natural science. Hence, it has greater exploratory abilities (including those concerning nature). However, on principle they exclude empirical cognition connected with natural sciences.

Considering the issue of the hypothesis in the humanities, it is possible to distinguish in their field such disciplines which in their specialized methodologies do not take into account any methods of empirical character (like general history or philosophy) and those disciplines which refer to them (like sociology, psychology, pedagogy, political science, economy, and others) introducing such exploratory instruments which are specific to them - and not to natural sciences - as surveys, interviews, and participant observation. The humanities may - and sometimes even must - refer to empirical data from the field of natural sciences, but they do so in an indirect way, for example, philosophy of nature, philosophy of cosmos, philosophy of man, and philosophy of biology.

Hence a wider range of questions and connected exploratory inspirations, as well as a broader variety of possible answers creating cognitive material necessary in the process of explaining and predicting, are justified there.

The hypothesis includes provisional answers not only to the question of "why?" but also the questions "when?", "where?", "how?", etc.

The procedure of testing (checking) the hypothesis is also understood more broadly in the humanities. Herbut points out that, for example, from a hypothesis of historiographic character it is sometimes possible to derive only "weakened" consequences (if $H$, then usually $B$ ) or implications that are not perceptive propositions. In the humanities inquiries have, to a greater or lesser degree, hermeneutic character. On that account, the hypothesis is entangled in a so-called "hermeneutical circle". A historian exploring some selected event from the past has some "pre-understanding" of it. This may be transformed into a hypothesis gradually, by mutually conditioned and alternating activities, that is, by widening source information and clarifying the initial intuition. 
We are dealing with a reliable historical hypothesis only when the researcher has studied source materials that are accessible in a given time and are connected with the issue taken up and when - not having found any solution - she/he formulates his/her own proposal. This has the status of the hypothesis until it is confirmed or invalidated by new historical sources. After its full confirmation the hypothesis becomes a proposition describing some fact from the past (Herbut, 2003, p. 488).

The issue of the philosophical hypothesis is broadly discussed by Mieczysław Albert Krapiec. He calls it the metaphysical hypothesis and maintains that it is a predicative proposition - not proved as necessarily true in a given philosophical system. Putting forward a metaphysical hypothesis is one of the ways (a way of secondary character) of explaining some states and processes of the really existing reality (Krappiec, 2003, p. 448).

Metaphysics (a polysemous notion) may be understood in its relation to the hypothesis as explanation of - and, simultaneously, prediction about - the physical world (the finite, material, natural, indirect, sensual, empirically accessible, aposteriorical, empirical or inductive, accidental being) by referring to the context of justification transcending the physical world.

An example in that respect is an Aristotelian hypothesis concerning the existence of the First Mover or the First Cause - in other words, God-Mind; that is, God justifying functioning of nature, of the whole universe. According to assumptions by the author of "Metaphysics" - that is, on the basis of evidence of cosmological, extraspective character, on the basis of sensual reception of closer or more distant nature, on the basis of data concerning cosmos - God surely exists. Aristotle maintained, like all earlier philosophersnaturalists, that matter is in continuous and eternal motion. If matter is in motion, the whole universe is in motion too. Hence, there must exist the First Mover, the perfect being of divine character. Aristotle added moreover that the functioning of nature is also based on cause-and-effect relations, that there exists a chain of causes influencing each other and of the connected results. Hence, there must exist and surely does exist the First Cause; that is, the perfect being of divine qualities (Aristotle, 1983, p. 314 and 317; Kosiewicz, 1999, pp. 13-38, 2012, pp. 91-92).

However, a typical inductive reasoning does not take place in that case, since the very process of concluding - Aristotle's final conclusion - is not logically justified; that is, the fact that in nature there exist movement and cause-and-effect relations does not justify the conclusion that there exist the God-Mover and the God-Cause preceding and initiating that movement. In that case we are dealing, among other things, with an ungrounded extrapolation, with a logical mistake, with a badly applied logical syllogism. The context of justification, based on cosmological (as well as anthropological) arguments is insufficient in that respect (Kosiewicz, 1999, pp. 13-38).

On the other hand, we may suppose that a hypothesis concerning such a God's existence is justified. However, its logical value - that is truth or falsity - cannot be checked in any empirical or non-empirical way. It can be neither confirmed nor rejected. It is a metaphysical hypothesis, because grounds for sensual and natural facts are sought in an abstract world situated beyond physical sensations - that is, in metaphysics, in something which is not a physical being and which refers to phenomena, to the physical world.

That metaphysics is accessible only through intuitive and simultaneously direct non-empirical cognition - that is, without an intermediate stage based on experience and induction. This means that it is impossible to pronounce anything about the metaphysical, abstract, apriorical, ideal, spiritual, divine being on the basis of sensual receptors since it is accessible only through variously interpreted, described, and defined intuition.

Hence, Aristotle's conclusion concerning the existence of God and his creative qualities is only an intellectual intuition, deductive-hypothetic reasoning, a metaphysical hypothesis, and not ascertainment and confirmation of the existence of real and simultaneously supernatural reality.

The metaphysical hypothesis may be considered in a different way to how it is presented by Krapiec in his statement on that issue (Krąpiec, 2003, pp. 488-499). Namely, the notion of "metaphysics" means according to the Lublin School and its proponents, as well as Ajdukiewicz and others - means the same as 
ontology or the theory of being, the science of being - that is, as a matter of fact, the philosophy of being. For that reason, the metaphysical hypothesis is understood as a hypothesis concerning the being considered only from the viewpoint of philosophy - that is, in a philosophical context of justification, since metaphysics (similarly to ontology, etc.) is treated solely as a branch of philosophy. Thus, in that case we are dealing with a statement on reality, on facts formulated on the basis of the general hypothesis.

Hence, the metaphysical hypotheses may be divided into the hypotheses concerning ideal beings and the hypotheses concerning material beings.

In the first case, it is possible to distinguish, among others, between the Aristotelian interpretation and the Platonic interpretation. The metaphysical hypothesis according to Aristotle has been discussed above. The first subject of cognition (according to the interpretation of the philosopher from Stagyra) is nature, and reflection on it leads to hypothetic explaining and predicting rooted in the being external in its relation towards nature - that is, in the supernatural being.

On the other hand, Plato's cosmology is focused first of all on the ideal world, which it regards as the only real one. Nature is to constitute the secondary being, miserable reflection - shadows - of eternal ideas. This is explained by metaphysical hypotheses perceiving the Demiurge, eternal ideas and matter as reasons of the origin of the primarily perfect natural world (then undergoing degradation) (Plato, 1986, p. 41; Kosiewicz, 2012). In Aristotle's case, his metaphysical hypotheses are suspended between Earth and heaven as a result of aposteriorical inspiration. On the other hand, in Plato's writings metaphysical hypotheses are suspended between heaven and Earth - they come into being as a result of apriorical inspiration.

The other type - that is, the hypothesis concerning sensually perceived beings, is metaphysical in the sense that it admittedly refers to nature, but that a philosopher who formulates it does not use - while aiming at its confirmation, rejection, or modification - empirical research concerning nature, since contemporary philosophy, including philosophy of nature, abstains in a principled way from methodologies of specialized empirical sciences as such, and especially of sciences on nature and biological sciences. This refers to nature in an indirect way - only on the basis of achievements of particular empirical sciences. It does not carry out strictly physical research. It creates hypotheses, which go beyond empirical and physical data. Hence, it formulates metaphysical hypotheses.

The metaphysical hypothesis discussed above has been regarded from a twofold viewpoint. Firstly, it was treated as an explanation (of nomotetic and nomological character) and a prediction concerning various and manifold aspects of facts regarded from the ontological viewpoint. Secondly, it was regarded as an intellectual intuition referring in its contexts of justification to the supernatural, abstract, and ideal world.

Hence, it is worth pointing out - taking into account the first interpretation - some difficulties in classifying that hypothesis. On the one hand, it may be assumed that a hypothesis, which in its context of justification refers only to animate or inanimate nature is not a metaphysical hypothesis (leaving nature aside) but a materialistic hypothesis. That standpoint seems to be justified when it is assumed that the notion of matter as such results from empirical cognition, that it refers to specific, sensually perceived, various and manifold (in quantitative and qualitative sense) facts and phenomena.

On the other hand, it may be assumed that matter as such does not exist at all, that it is possible to perceive only single or collective beings of a greater or lesser degree of complexity, of organic and nonorganic qualities. Each of those beings has its own individual - and, possibly, species-specific features distinguishing it from others. This is one of the reasons for maintaining that the materialistic hypothesis assuming the existence of matter is, as a matter of fact, a metaphysical hypothesis, because matter is only a notion, an abstraction - that is, a being which does not exist in the sensual sense.

Independent of the above digression, it should be pointed out that metaphysical hypotheses functioning on philosophical foundations concern not only ontology but also other branches of philosophy. All explanations appearing in them have a solely metaphysical character - they either refer indirectly to empirical research, or exclude them on principle. 
For example, in the field of axiology various possibilities are considered concerning the source of values. Those explanations are solely hypothetic. This refers to, among others, objectivism (objective, e.g., in the meaning of Platonic existence of values), universalism (universal, e.g., in the meaning of Platonic existence of values), subjectivism (assuming, among others, that the human subject is the source of values), relativism (pointing out that values are relative and dependent on many factors), relationism (assuming that values have social character and are born in human relations, configurations, connections).

On the other hand, in epistemology there are various standpoints pointing out the cognitive possibilities, sources of knowledge and wisdom. They have hypothetic character. For example, Immanuel Kant maintains on the grounds of transcendental aesthetics that time and space have strictly subjective individual qualities. That metaphysical hypothesis of gnoseological character has a well-developed context of justification included in Critique of Pure Reason (Kant, 1986, pp. 95, 107-108, 109, 111, 115; Kosiewicz, 2012). Admittedly, this refers to space and time, which are physically and empirically perceived in an observable and measurable way - as well as experienced in a common-sense way - but, nevertheless that hypothesis has a typically metaphysical character. That is because of the fact that it refers to the abstract and non-physical being, which is definable neither partly, nor as the whole. In that sense, Kant's statement of apriorical qualities of space and time is a hypothesis based on intellectual intuition in the strictest sense of the word (regarding the source of inspiration) and, from that viewpoint, it is a metaphysical hypothesis.

In ethics there is also a domination of explanations of hypothetical character, e.g. the groundwork of the metaphysics of morals in Kant's philosophy $(1971,1984)$. Kant points out that the source of morality is the "starlit sky" - the noumenal world (which is non-phenomenal and metaphysically inaccessible for human senses). The context of justification is based on assumptions and a method characteristic for philosophical intellectual intuition.

Similar examples may be quoted by referring to other branches of philosophy - that is, to aesthetics, social philosophy, or philosophical anthropology. All explanations and predictions (concerning for example social changes or the aim and the end of the humankind's development in Aurelius Augustine's (1977) philosophy have hypothetical character. Thus, in the case of philosophy we are also dealing with hypothetism, but understood differently than in Popper's case.

In the field of the discussed, branch thinkers will not aim at empirical falsification of their views, but they will rather assume, like Kant or Hegel did, that their hypotheses - explanations and the connected predictions - are true pieces of reasoning not only in the context of a given theory, but also in the context of the whole speculative philosophical system (Hegel's considerations concerning natural and supernatural reality or Kant's statements referring to the phenomenal and the noumenal world may serve as examples). However, the history of philosophy presents evidence for philosophical defeats - that is, for failures of hypotheses, theories, circles, schools, currents, etc. Everything suggests that this trend - and, simultaneously, a property of philosophy - will remain. Thus, on the grounds of philosophical studies, there also function (as it seems, in a more consistent way) hypothetism, falsificationism and fallibilism, but their source is - in contrast with Popper's case - cognitive activity of non-empirical (and - in that sense - metaphysical) character with the basis constituted by a metaphysical hypothesis. It may even be assumed that the outstanding - and innovative in their time - views of Popper in the fields of philosophy of science, methodology, and science studies connected with natural sciences (which have been criticized many times in various and more or less justified ways) turn out to be the most appropriate (sic!) when referred to philosophy as such and to those of the humanities, which completely or partly give up empirical cognition as the basis of the specialized methodology of their research. History of philosophy points out that the basis of all theories is constituted by hypotheses, which in the course of the historical process are submitted to quicker or slower, but constantly progressing falsification. Falsification is necessary for at least two reasons:

1. As a necessary factor of further philosophical activity. Without partial negation and, simultaneously, modification or complete rejection of existing views, there is no development of the history of 
philosophy as such. If that phenomenon, which is permanent and universal on philosophical grounds and simultaneously constitutes a categorical imperative, were absent - and views of contemporary or past thinkers were not rejected - then the historicity of philosophy would stop, for example, on the level of conceptions and thoughts of Thales from Miletus or, finally, with Hegel's genial work. They were to constitute, in his opinion, the final effect of self-realization and self-affirmation of Minerva's owl, flying only at dusk and ascending to the absolute abstraction. That was to be the end of the development of philosophy as such (Hegel, 1963; Kosiewicz, 2004b, pp. 3-15; Kosiewicz, 2006, pp. 90-101). However, philosophy, as it soon turned out, did not finish its flight. Hegel's work did not prove to be its end.

2. As a testimony to content-related or formal mistakes included in theoretical considerations (based on hypotheses). Philosophical activity continues and, in spite of growing activity in the field, it is said that it is in a permanent crisis. That crisis is just a testimony to constant, inseparable, and necessary falsification. That phenomenon is by no means objectivisation of development of philosophy as such - that is, aiming at the absolute abstraction, its constant improvement. Progressing falsification - and philosophical activity, which is inseparably connected with it as its reason and effect - is only the legitimization of constant striving for describing, explaining, and predicting, for achieving as much knowledge as possible. It is not, however, the same as real improvement, deepening, and evolutionary development of philosophy.

We are dealing, first of all, with the growth of philosophical activity, as is testified by its historicity, which is simultaneously a context justifying and objectifying its constant crisis, its permanent falsification and the necessity of maintaining a science game - that is, a philosophy game - which is constantly more or less consciously played by philosophers. On its stage (that is, in the field of philosophy) there constantly appear new explanations, hypotheses and theories. They take part for a longer or shorter time in the cognitive game and are eliminated to make room for new solutions, based on contexts of justification, which are (currently, but not universally) more convincing. When a mistake, a shortcoming, or an incoherence is noticed in them, they are submitted to degradation, decline, and rejection (conditions of sense - that is, of preservation - of philosophical views are discussed in the next paragraph). A phenomenon of fallibilism takes place, which is connected with falsification, but concerns non-empirical (apriorical) hypotheses and theories - in contrast with the model-like Popperism focusing its attention on data from the field of natural sciences.

Krąpiec is of the opinion that metaphysical hypotheses (that is, such propositions which are not proved as necessarily true) may be recognized as semantically sensible when they: a) are internally noncontradictory propositions, b) explain (and predict - my interjection) some real facts which have not been explained so far, c) are not contradictory to other propositions belonging to the system of metaphysics, and d) are coherent with the philosophical system and fill a gap in the system of metaphysics (that is, in philosophy of being - my interjection).

The Lublin philosopher supplements his opinion by pointing out that it is not necessary for hypotheses to meet all the abovementioned conditions. For example, internal contradiction is in Hegel's philosophical and metaphysical system a bearer of truth and constitutes the basis of a holistically understood theory of truth.

Metaphysical hypotheses are more or less probable and the level of their probability depends on meeting a greater and greater number of the abovementioned conditions. Less probable hypotheses are those, which do not meet the last condition, that is, they do not fill a gap in the metaphysical system. Differentiation of metaphysical hypotheses of various levels of probability makes it possible to perceive weak points in the metaphysical system and to improve it (Krąpiec, 2003, p. 489).

Nota bene, the level of probability of metaphysical hypotheses of philosophical provenance is something different to probabilistic hypotheses in the humanities, which apply in their specialized methodologies' empirical methods. 
Probabilistic hypotheses play an important role not only in contemporary natural sciences, but also in social sciences, where general and categorical propositions ascribing a definite property to all elements of a given set are rare. What is characteristic for them are propositions concerning frequency of a given quality in a given set, that is, probabilistic propositions. Even if the probability of a given event is very high - e.g. $99 \%$ - it is not certain, there is no guarantee that the event will take place. And vice versa - rare events do take place in reality.

Sociological, economical, and demographical laws usually have statistical (empirical) character). Hence, predictions (hypotheses), which are based on them have probabilistic qualities. This is also connected with a high complexity of social processes, with numerous factors interfering with their course. Moreover, laws, which are formulated in the area of social sciences, usually concern idealizing models and they can be - but with great caution and after various specifications and revisions - applied in practice. This is one of the reasons why probabilistic hypotheses from the field of social sciences (the humanities) are unfortunately rather unreliable (Krajewski, 1998, p. 189).

\section{Conclusion}

The presented text consists of two basic parts. The first includes reminiscences and the associated methodological resentment. The second presents a wide panorama of standpoints concerning functions and kinds of hypotheses, their role and significance in contemporary research programs of a formal, empirical (connected with natural sciences and biology), and humanities nature. Sketchy and encyclopaedic interpretations, presented in the context of commentaries by the author of the presented paper, thereby dominate.

The aim of the first part was to draw attention to some methodological mistakes which often appear and which have become commonplace in some academic milieus to such a degree that some intervention and postulatory correction, referring to Polish and Western methodological literature, is advisable. Those shortcomings are connected, among others, with the structure of the scientific work, with the formulation and application of hypotheses, with relationships between the general methodology and specialized methodologies, kinds, and types of research work, with reliability of information on sources of creative information, as well with the category of verification in its relation, on the one hand, to confirmation and corroboration and, on the other hand, to testing, checking, falsification, and terms close in meaning to the last one.

The abovementioned resentment results, first of all, from the fact that the authors mentioned in the first part usually insist on erroneous solutions, negating a priori, without becoming acquainted with the literature on the subject or making attempts to explain or initiate a methodological argument referring to sources and studies. That resentment is significant, among others, in the causal sense - that is, because of the fact that, first, it justifies and substantiates the need for a statement presenting controversial questions in a content-related and formal way. Second, because thanks to such (that is, cognitive-emotional) introduction, the whole argument - not only in the first, but also in the second part - is much more interesting. It is saturated with authenticity. Many readers know the figures mentioned and their - sometimes too insouciant (sometimes not very reliable) - attitudes to important issues from the field of research methods. It is also interesting to consider why the people referred to make mistakes. Hence, it is also advisable to look at a wider methodological context of justification (included in the much longer second part) dedicated to perhaps the most thorough characteristics of the hypothesis in the literature on the subject, which is available to the author. Without presentation of the controversial issues in the first part, the second part, more important from the methodological viewpoint, might be omitted by a considerable proportion of readers.

\section{REFERENCES}

Ajdukiewicz, K. (1938). Logiczne podstawy nauczania /Logical Foundations of Teaching/. Warszawa-Wilno. 
Ajdukiewicz, K. (1948). Metodologia i metanauka /Methodology and Metascience/. Życie Nauki, 14-15, 31-32.

Ajdukiewicz, K. (1985a). Metodologiczne typy nauk /Methodological Types of Science/. In K. Ajdukiewicz, Język $i$ poznanie /Language and cognition/, vol. 1 (pp. 87-313). Warszawa: PWN.

Ajdukiewicz, K. (1985b). Metodologia i metanauka /Methodology and Metascience/. In K. Ajdukiewicz, Język $i$ poznanie /Language and cognition/, vol. 2 (pp. 117-126). Warszawa: PWN.

Aristoteles (1983). Metafizyka /Metaphysics/. Warszawa: PWN.

Aureliusz Augustyn (1977). O państwie Bożym /The City of God/. Warszawa: PWN.

Braithwaite, R. (1953). Scientific explanation : a study of the function of theory, probability and law in science. Based upon the Tarner lectures. Cambridge: University Press.

Bryman, A. (2004). Social Research Methods. $2^{\text {nd }}$ Edition. New York: Oxfrod University Press.

Carnap, R. (1969). Sprawdzalność i znaczenie /Verifiability and Meaning/. In R. Carnap, Filozofia jako analiza języka nauki /Philosophy and Logical Syntax/ (pp. 70-79). Warszawa: PWN.

Carnap, R. (1935). Logical Syntax of Language. In R. Carnap, Philosophy and Logical Syntax. London: Kegan Paul, Trench, Trubner \& Co.

Carnap, R. (1973) Neopozytywistyczna koncepcja weryfikacji w ujęciu Carnapa /Neopositivist Conception of Verification According to Carnap's Interpretation/. In B. Mejbaum, W. Mejbaum (Eds.), Gtówne zagadnienia filozofii i socjologii marksistowskiej /The Main Problems of Marxist Philosophy and Sociology/ (pp. 839-854). Łódź: Wydawnictwo Akademia Medyczna w Łodzi.

Chmielewski, A. (2007). Popper. In Powszechna encyklopedia filozofii /Universal Encyclopedia of Philosophy/ (pp. 359-365) . Lublin. Polskie Towarzystwo Tomasza z Akwinu.

Colodny, R.G. (Ed). (1969). The Nature \& function of scientific theories; essays in contemporary science and philosophy. Vol 4. Pittsburgh: University of Pittsburgh Press.

Dąmbska, I. (1975). O konwencjach i konwencjonalizmie /On Conventions and Conventionalism/. Wrocław: Zakład Narodowy im. Ossolińskich.

Demel, M. (1968). O wychowaniu zdrowotnym /On Health-Related Education/. Warszawa: Państ. Zakłady Wydawnictw Szkolnych.

Demel, M. (1980). Pedagogika zdrowia /Pedagogy of Health/. Warszawa: Wydaw-a Szkolne i Pedagogiczne.

Domański, J. (1996). Metamorfozy pojęcia filozofii /Metamorphoses of the Notion of Philosophy/. Warszawa: Wydawnictwo IFiS PAN.

Duhem, P. (1904). Ewolucya mechaniki /Evolution of Mechanics/. Warszawa: Wydawnictwo Redakcyi "Wiadomości Matematycznych".

Duhem, P. (1906). La théorie physique, son objet et sa structure /The Aim and Structure of Physical Theory/. Paris: Chevalier et Riviere.

Feyerabend, P. (1970). Against the method. Minnesota Studies for the Philosophy of Science, 4.

Feyerabend, P. (1975). Against the method: outline of an anarchistic theory of knowledge. London: NLB.

Feyerabend, P. (1979). Jak być dobrym empirysta /How to Be a Good Empiricist/. Warszawa: Państ. Wydaw. Nauk.

Fleck, L. (1986). Powstanie i rozwoj faktu naukowego : wprowadzenie do nauki o stylu myślowym i kolektywie myślowym /The Genesis and Development of a Scientific Fact: An introduction to the Science of Styles of Thinking and the Collective Thinking/. Lublin: Wydawnictwo Lubelskie.

Gratton, C., Jones, I. (2005). Research Methods for Sport Studies. London and New York: Routledge.

Hegel, G.W.F. (1963). Fenomenologia ducha /Phenomenology of Spirit/. Warszawa: PWN.

Hempel, C.G. (1945). Studies in the Logic of Confirmation, Mind, 54.

Hempel, C.G. (1962). Deductive-Nomological versus Statistical Explanation. Minnesota Studies in the Philosophy of Science, 3.

Hempel, C.G., Oppenheim, P. (1965). Studies in the Logic of Explanation. In C. Gustav, Aspects of scientific explanationand other essays in the philosophy of science. New York: Free Press, London: Collier-Macmillan.

Hempel, C.G. (1968). Podstawy nauk przyrodniczych /Philosophy of Natural Sciences/. Warszawa

Herbut, J. (2003). Hipoteza/Hypothesis/. In Powszechna encyklopedia filozofii /Universal Encyclopedia of Philosophy/, vol. 4 (pp. 487-488). Lublin: Polskie Towarzystwo Tomasza z Akwinu.

Hume, D. (1947). Badania dotyczace rozumu ludzkiego /An Enquiry Concerning Human Understanding/. Kraków: PWN.

Hume, D. (1963). Traktat o naturze ludzkiej /Treatise of Human Nature/. Warszawa: PWN. 
Hume, D. (1974). Związek konieczny /On the Idea of Necessary Connexion/. In S. Jedynak, Hume. Warszawa: Wydawnictwo "Myśl i Ludzie".

Jevons, W.S. (1960). Zasady nauki: traktat o logice i metodzie naukowej. /Principles of Science: A Treatise on Logic and the Scientific Method/. Warszawa: Państwowe Wydaw. Naukowe.

Kamiński, S. (1981). Metoda i nauka. Pojęcie nauki i klasyfikacji nauk/Method and Science. The Notion of Science and Classification of Sciences/. Lublin: Polskie Towarzystwo Tomasza z Akwinu.

Kant, I. (1971). Uzasadnienie metafizyki moralności/Groundwork of the Metaphysics of Morals/. Warszawa: PWN.

Kant, I. (1984). Krytyka praktycznego rozumu /Critique of Practical Reason/. Warszawa: PWN.

Kant, I. (1986). Krytyka czystego rozumu /Critique of Pure Reasoin/. Warszawa: PWN.

Kawalec, P. (2003). Hipotetyzm /Hypothetism/. Powszechna encyklopedia filozofii /Universal Encyclopedia of Philosophy/. Lublin: Wydawnictwo KUL.

Kmita, J. (1975). Wykłady z logiki i metodologii nauk /Lectures on Logic and Methodology of Science/. Warszawa: PWN.

Kosiewicz, J. (1988). Pierre de Coubertin - w kręgu Olimpii i Laokoona /Pierre de Coubertin - in the Circle of Olympia and Laocoon/. Sport Wyczynowy, 7-8.

Kosiewicz, J. (1996). Metodologia jako forma agnostycyzmu /Methodology as a Form of Agnosticism/. Edukacja Filozoficzna, 22, 275-287.

Kosiewicz, J. (1999). Bóg i afirmacja, czyli o pewności istnienia Boga /God and Affirmation - on Certainty of God's Existence/. In Bóg, cielesność i miłość /God, corporality, and love/ (pp. 13-37). Warszawa: Aletheia.

Kosiewicz, J. (2004a). Rozważania o pojęciu i metodologii nauk o kulturze fizycznej /Considerations on the Notion and Methodology of Physical Culture Sciences/. In J. Kosiewicz, Filozoficzne aspekty nauk o kulturze fizycznej $i$ sporcie /Philosophical Aspects of Physical Culture and Sport/ (pp. 65-83). Warszawa: Wydawnictwo „BK”.

Kosiewicz, J. (2004b). Hegel - człowiek jako niezbędne i centralne ogniwo w procesie samorealizacji Absolutu /Hegel - Man as a Necessary and the Central Link in the Absolute's Self-Realisation/. Roczniki Naukowe AWF, XLIII, 3-15.

Kosiewicz, J. (2006). Boxing Fight as a Manifestation of Movement Towards Absolute Abstraction: An Analysis from the Viewpoint of Hegelian Phenomenology of Spirit. Moving Bodies. Ethical Expertise, Phronesis and Moral Education, 4, 91-101 Oslo.

Kosiewicz, J. (2010). O metodologii i hipotezie /On Methodology and Hypothesis/. In W. Słomski (Ed.), Język $i$ poznanie. W 120. rocznice narodzin Kazimierza Ajdukiewicza /Language and Cognition: The 120 $0^{\text {th }}$ Anniversary of the Birthday of Kazimierz Ajdukiwiecz/ (pp. 21-85). Warszawa: Wyższa Szkoła Finansów i Zarządzania.

Kosiewicz, J. (2012). Free Time versus Occupied and Unoccupied Time in a Philosophical Context. Physical Culture and Sport. Studies and Research, LV, 77-94. DOI: 10.2478/v10141-012-0015-2.

Krajewski, W. (Ed). (1972). Pojęcie prawa nauki a konwencjonalizm XX wieku /The Notion of Science and $20^{\text {th }}$ Century Conventionalism/. Wrocław: Ossolineum.

Krajewski, W. (1998). Prawa nauki. Przeglad zagadnień metodologicznych i filozoficznych /Laws of Science. A Review of Methodological and Philosophical Issues/. Warszawa: "Książka I Wiedza".

Krawczyk, Z. (2005). Selected Writings. In J. Kosiewicz (Ed). Sport, Culture and Society (pp. 21-161). Warsaw: Wydawnictwo ALMAMER.

Krawczyk, Z. (2006). Pisma wybrane /Selected Writings/. In J. Kosiewicz (Ed), Sport, kultura, społeczeństwo /Sport, Culture and Society/. Warszawa: Wydawnictwo ALMAMER.

Krąpiec, M.A. (2003). Hipoteza metafizyczna /Metaphysical Hypothesis/. In Powszechna encyklopedia filozofii. Lublin: Wydawnictwo KUL.

Kuhn, T. (1968). Struktura rewolucji naukowych /The Structure of Scientific Revolutions/. Warszawa: PWN.

Lakatos, I., Musgrave, A. (Eds). (1968). Problems in the philosophy of science. Studies in Logic and the Foundations of Mathematics, 3. Amsterdam: North-Holland Publishing Company.

Lakatos, I. (1990). Racjonalna rekonstrukcja odkryć naukowych /Rational Reconstruction of Scientific Notions/. Lublin.

Lakatos, I. (1995). Pisma z filozofii nauk empirycznych /Writings on Philosophy of Empirical Sciences/. Warszawa: PWN.

Levi, I. (1967). Gambling with truth: an essay on induction and the aims of science. New York: Alfred A. Knopf, London: Routledge and Kegan Paul.

Lewis, C.I. (1934). Experience and Meaning, Philosophical Review, 43.

MacAloon, J.J. (1984). This great symbol. Pierre de Coubertin and the origins of the modern olympic games. Chicago, London:The University of Chicago Press. 
Mazierski, S. (1993). Prawa przyrody: studium metodologiczne /Laws of nature: A Methodological Study/. Lublin: Redakcja Wydawnictw KUL.

Mill, J.S. (1962). System logiki dedukcyjnej i indukcyjnej /A System of Logic/. Warszawa: Państwowe Wydaw. Naukowe.

Mortimer, H. (1987). Indukcja /Induction/. In Filozofia a nauka. Zarys encyklopedyczny /Philosophy and Science: An Encyclopedic Outline/. Wrocław: Ossolineum.

Nagel, E. (1934). Verifiability, Truth and Verification. Journal of Philosophy, 31.

Nagel, E. (1970). Struktura nauki /The Structure of Science/. Warszawa: PWN.

Podsiad, A. (2000). Słownik terminow i pojęć filozoficznych /Dictionary of Philosophical Terms and Notions/. Warszawa: "Pax".

Podsiad, A., Więckowski, Z. (1983). Mały stownik terminow i pojęć filozoficznych dla studiujących filozofię chrześcijańska /A Small Dictionary of Philosophical Terms and Notions for Students of Christian Philosophy/. Warszawa: „Pax”.

Poincaré, H. (1908) Nauka i hipoteza /Science and Hypothesis/. Warszawa: Jakob Mortkowicz, Lwow : H. Altenberg.

Poincaré, H. (1911). Nauka i metoda /Science and Method/. Warszawa.

Popper, K. (1935). Logik der Forschung; zur erkenntnistheorie der modernen naturwissenschaft /The Logic of Scientific Discovery/. Vienna: J. Springer.

Popper, K. (1977). Logika odkrycia naukowego /The Logic of Scientific Discovery/. Warszawa: PWN.

Popper, K. (1992). Wiedza obiektywna: ewolucyjna teoria epistemologiczna /Objective Knowledge: An Evolutionary Approach/. Warszawa: Wydaw. Naukowe PWN.

Pseudo-Platon. (1973). Alkibiades $i$ i inne dialogi oraz definicje /Alkibiades and Other Dialogues and Definitions/. Warszawa: PWN.

Reinchenbach, H. (1936). Logistic Empiricism in Germany and the Present State of its Problems. Journal of philosophy, 33.

Schlick, M. (1936). Meaning and Verification. Philosophical Review.

Szaniawski, K. (1987). Hipoteza /Hypothesis/. In Filozofia a nauka. Zarys encyklopedyczny (pp. 197-208). Wrocław: Ossolineum.

Siemianowski, A. (1983). Fakty, prawa, decyzje (rozprawy o konwencjonalistycznej filozofii nauki). /Facts, Laws, Decisions (Considerations on the Conventionalist Philosophy of Science)/. Prace Naukowe Akademii Ekonomicznej im. Oskara Langego. Monografie i opracowania, nr 245. Wrocław: Wydawnictwo Uczelniane Akademii Ekonomicznej.

Siemianowski, A. (1987). Konwencjonalizm /Conventionalism/. In M. Ilżewska (Ed.), Filozofia a nauka. Zarys encyklopedyczny /Philosophy and Science: An Encyclopedic Outline/ (pp. 322-330). Wrocław: Zakład Narodowy im. Ossolińskich.

Whewell, W. (1851). On the Transformation of Hypotheses of Science. Cambridge Philosophical Transactions, 9.

Whewell, W. (1847). The Philosophy of Inductive Science, founded upon their history. London.

Wittgenstein, L. (1922). Tractatus Logico-Philosophicus. New York: Harcourt, Brace \& company,inc., London: K. Paul, Trench, Trubner \& co.

Wójcicki, R. (1982). Wyktady z metodologii nauk/Lectures on Methodology of Sciencel. Warszawa: PWN.

\section{AUTHOR'S ADDRESS: $\quad$ Jerzy Kosiewicz}

Department of Philosophy and Sociology, Chair of the Social Sciences

Josef Pilsudski University of Physical Education in Warsaw

34 Marymoncka str., 00-968 Warsaw, Poland

Email: jerzy.kosiewicz@awf.edu.pl 